\title{
Imaging-Guided Delivery of a Hydrophilic Drug to Eukaryotic Cells Based on Its Hydrophobic Ion Pairing with Poly(hexamethylene guanidine) in a Maleated Chitosan Carrier
}

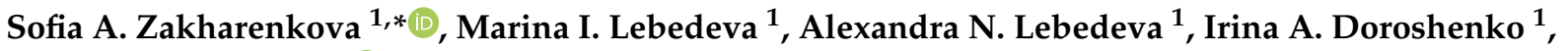 \\ Ksenya Yu Vlasova ${ }^{1,2}{ }^{-}$, Anastasiya A. Bartoshevich ${ }^{1}$, Vladimir M. Senyavin ${ }^{1}$, Sergey S. Abramchuk ${ }^{3}$, \\ George G. Krivtsov ${ }^{4}$, Alexander A. Ezhov ${ }^{5}$ (), Tatyana A. Podrugina ${ }^{1}$, Natalia L. Klyachko ${ }^{1,6,7}$ \\ and Mikhail K. Beklemishev ${ }^{1}$ (D)
}

check for

updates

Citation: Zakharenkova, S.A.; Lebedeva, M.I.; Lebedeva, A.N.; Doroshenko, I.A.; Vlasova, K.Y.; Bartoshevich, A.A.; Senyavin, V.M.; Abramchuk, S.S.; Krivtsov, G.G.; Ezhov, A.A.; et al. Imaging-Guided Delivery of a Hydrophilic Drug to Eukaryotic Cells Based on Its Hydrophobic Ion Pairing with Poly(hexamethylene guanidine) in a Maleated Chitosan Carrier. Molecules 2021, 26, 7426. https://doi.org/ $10.3390 /$ molecules 26247426

Academic Editors: Guido Viscardi and Andrea Fin

Received: 30 October 2021

Accepted: 3 December 2021

Published: 7 December 2021

Publisher's Note: MDPI stays neutral with regard to jurisdictional claims in published maps and institutional affiliations.

Copyright: (c) 2021 by the authors. Licensee MDPI, Basel, Switzerland. This article is an open access article distributed under the terms and conditions of the Creative Commons Attribution (CC BY) license (https:// creativecommons.org/licenses/by/ $4.0 /)$.
1 Department of Chemistry, Lomonosov Moscow State University, 119991 Moscow, Russia; marinal1807@gmail.com (M.I.L.); spottycucumber@yandex.ru (A.N.L.); doroshenkoiran@gmail.com (I.A.D.); vlasova_k.y@mail.ru (K.Y.V.); nastenabarto@mail.ru (A.A.B.); senyavin@phys.chem.msu.ru (V.M.S.); podrugina@mail.ru (T.A.P.); klyachko@enzyme.chem.msu.ru (N.L.K.); beklem@inbox.ru (M.K.B.)

2 Department of Medical Nanobiotechnology, Pirogov Russian National Research Medical University, 117997 Moscow, Russia

3 Laboratory of Physical Chemistry of Polymers, Nesmeyanov Institute of Organoelement Compounds (INEOS RAS), 119991 Moscow, Russia; abr@polly.phys.msu.ru

4 Mechnikov Research Institute for Vaccines and Sera, 105064 Moscow, Russia; invention1938@inbox.ru

5 Faculty of Physics, Lomonosov Moscow State University, 119991 Moscow, Russia; alexander-ezhov@yandex.ru

6 Center for Nanotechnology in Drug Delivery, Eshelman School of Pharmacy, University of North Carolina at Chapel Hill, Chapel Hill, NC 27599, USA

7 Institute "Nanotechnology and Nanomaterials", G.R. Derzhavin Tambov State University, 392000 Tambov, Russia

* Correspondence: sophie.chaplenko@gmail.com

Abstract: Imaging-guided delivery is developed for hydrophobic drugs, and to a much lesser extent, hydrophilic ones. In this work we have designed a novel strategy for real-time monitoring of hydrophilic drug delivery. Traditionally, the drug and the dye are covalently attached to a nanocarrier or are electrostatically adsorbed. Recently, we found an efficient way to bind the drug by ion-paring with an appropriate counter-ion to form the aggregate that embeds a hydrophobic dye with a considerable fluorescence enhancement. We synthesized a series of carbocyanine dyes of hydrophobicity sufficient for solubilization in hydrophobic ion pairs, which restores their emission in the near-infrared (NIR) region upon the formation of the ternary aggregates. To avoid using toxic surfactants, we applied an amphiphilic polymer-oligomer poly(hexamethylene guanidine) (PHMG) as a counter-ion. Ceftriaxone was used as a model hydrophilic drug ensuring the highest fluorescent signal. The so-formed drug-counter-ion-dye aggregates were encapsulated into a cross-linked maleated chitosan carrier. Confocal laser scanning microscopy (CLSM) studies have demonstrated internalization of the encapsulated model drug by breast adenocarcinoma cells at 40 min after treatment. These results suggest the potential application of hydrophobic ion pairs containing an NIR dye in imaging-guided delivery of hydrophilic compounds.

Keywords: carbocyanine dye; ceftriaxone; cross-linked maleated chitosan; hydrophobic ion pairing; imaging-guided drug delivery; poly(hexamethylene guanidine)

\section{Introduction}

A fair amount of drug delivery strategies to cells, tissues, and organs has been developed using various nanostructures [1,2]. Less attention was paid to the task of real-time monitoring of delivery [3-8]. Imaging-guided delivery of hydrophobic substances is a welldeveloped strategy, which is based on loading both the drug and a hydrophobic dye (prefer- 
ably emitting in the infrared (IR) or near-IR region, in one of the tissue transparency windows) into a nanocontainer $[9,10]$ and which allows the drug distribution to be monitored by the fluorescence of the dye until container destruction. Within that strategy, imagingguided chemotherapy was realized with doxorubicin (DOX) as the 'gold standard' of a model drug for cancer treatment using various nanocontainers: cross-linked chitosan with carbon dots as fluorophore [11], $\mathrm{N}$-naphthyl-O-dimethymaleoyl chitosan-modified magnetic nanoparticles with DOX as fluorophore [12]; a self-assembled glutathione-responsive porphyrin with DOXas fluorophore [3] and $\beta$-cyclodextrin-carbocyanine conjugate [4] were used to deliver DOX to HeLa cells. Paclitaxel was packed in magnetite-polystyrenepoly(lactic-co-glycolic acid) nanospheres with NIR quantum dots as fluorophore to treat tumors in mice [13].

As for hydrophilic drugs, they can easily penetrate the cell membranes without the use of any specific delivery vehicles. To neutralize the charge on an ionic drug, the surfactantlike counter-ions are applied to form hydrophobic ion pairs (HIPs) producing hydophobic complexes with the drug via electrostatic interactions [14]. HIPs are widely used in drug delivery $[15,16]$ but not in imaging. Delivery systems are also used for the hydrophilic drugs that show poor bioavailability through conventional routes of administration; those types of drugs can be delivered using nanoemulsions applied to the skin [17] or orally [18]. However, monitoring of the delivery of hydrophilic substances has been much less studied. Monitoring of this type of compounds can be based on covalent or non-covalent labeling of the container. Covalently attached fluorescent label [5,6] indicates the position of the nanocontainer, but does not reveal its destruction. A more promising approach is reversible non-covalent labeling of the drug $[7,8,19]$, which not only eliminates the covalent bond formation, but preserves the chemical identity of the delivered compound and also makes it possible to observe the destruction of the container upon drug release. There are few examples of using hydrophobic ion pairing or self-assembly for imaging of hydrophilic drugs: nicardipine was imaged by quenching an anthracenic dye in the chitosan nanocontainer and regaining fluorescence upon drug release [8]; cysplatin prodrug was electrostatically linked to carbon dots, incapsulated into a polymeric shell [7]; a multifunctional nanocarrier containing an $\mathrm{SN}-38$ antitumor agent was assembled with a carbocyanine dye [19]. However, too rapid release of a drug attached by adsorption can present a problem of non-covalent drug binding [20]. A more general approach to strong non-covalent binding would be well-suited for monitoring the hydrophilic drugs.

Hydrophobic ion pairing is an appropriate type of binding for a hydrophilic drug when its imaging is required. As we have recently shown [21], HIPs (for example, formed by cephalosporin anion and cetyltrimethylammonium cation) can incorporate a hydrophobic dye with a considerable fluorescence enhancement. We synthesized [21] a new series of pentamethine carbocyanine dyes with appropriate hydrophobicity to be solubilized in the HIPs. In aqueous buffer solution, the dye exists as nanoparticles, and its fluorescence is quenched (aggregation-induced quenching [22]). The bright emission in the near-IR region is restored when the dye enters the hydrophobic domains of the HIPs formed by the alkyl chains of the counterion (for example, cetyltrimethylammonium). We consider that these systems could be suitable for non-covalent imaging of a hydrophilic drug as a component of the ion pair. The incorporated dye-containing fluorescent HIPs ("ternary aggregates" [21]), when placed in an appropriate nanocarrier, may indicate the position of the drug in the organism. Moreover, it will be possible to observe the nanocontainer lysis that might be predictably accompanied by a change in the quantum yield of the IR fluorophore upon contact with the internal milieu.

For the transfer of the ternary aggregates across cell membranes, we obtained their complexes with anionic chitosans, widely used as a drug delivery vehicle. Chitosan is regarded as a biocompatible, biodegradable, and non-toxic biomaterial, easy modifiable and useful as a drug carrier [23,24]. Anated chitosans are considered promising in drug delivery due to their lower toxicity and favorable permeation properties. Carboxymethylated chitosan is one of the best studied [25], although less attention has been paid to other 
anionic chitosans [26]. In this work, we evaluated the possibility for formation of nanocarriers containing fluorescent hydrophobic ion pairs (ternary aggregates), which carry an NIR fluorescent dye, using both maleated and carboxymethylated chitosan cross-linked with dialdehydes (see Scheme 1 for the structures and Scheme 2 for the overall diagram of the processes). Such hydrophilic containers were regarded unsuitable for imaging-guided delivery based on the quantum yield change of the dye, since it was difficult to encapsulate the hydrophobic dye into a hydrophilic container and because water penetrated the container rapidly with dye emission quenching [22]. In our work both these difficulties have been overcome by placing the dye into the novel ternary aggregate drug-counter-ion-dye, which was then encapsulated into anated chitosan. The aggregate itself is hydrophilic and only contains the hydrophobic domains intended to hold the dye.

a<smiles>CO/C=C(/C(=O)N[C@H]1C(=O)N2C(C(=O)O)=C(CSc3nc(=O)c(=O)[nH]n3C)CS[C@H]12)c1csc(N)n1</smiles>

C

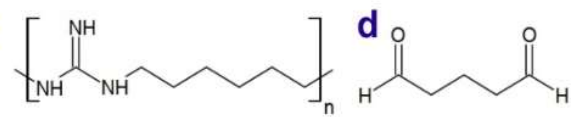

e<smiles>CCCCCCCCCCCCCCCCC[N+](C)(C)C</smiles>

f

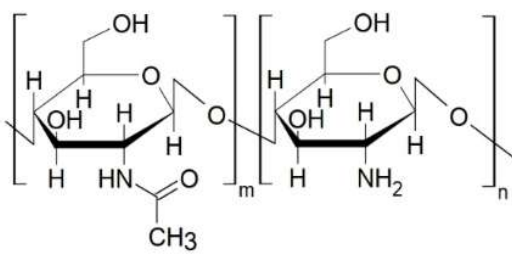

b

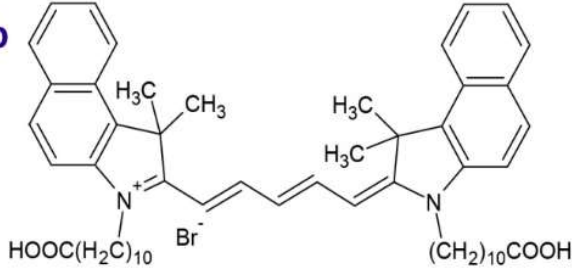

g

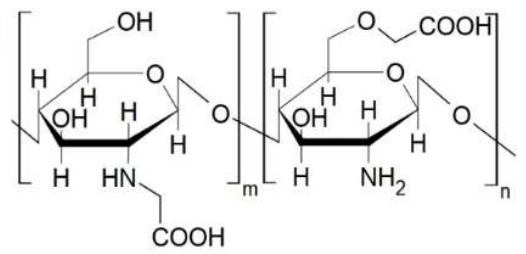

h

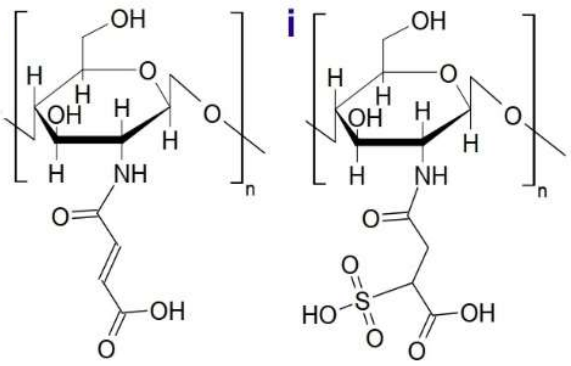

Scheme 1. Structures of ceftriaxone (a), dye (b), poly(hexamehtylene guanidine) (PHMG) (c), glutaraldehyde (d), cetyltrimethylammonium bromide (CTAB) (e), non-modified chitosan (f), carboxymethylated chitosan (g), maleated chitosan (h), maleated sulfated chitosan (i). In the chitosans $(\mathrm{g}-\mathbf{i})$, not all repeating units are substituted by the introduced groups.

The purpose of this study is to assess the feasibility in application of the dye-containing chitosan-encapsulated ternary aggregates for the delivery of a hydrophilic drug to eukaryotic cells. We used ceftriaxone as a model drug, which is known to form [21] stable ternary aggregates with CTAB and capable of fluorescence enhancement of a pentamethyne carbocyanine dye. We replaced the toxic surfactant (CTAB) used as a counter-ion in [21] with a cationic polymer-oligomer poly(hexamethylene guanidine) (PHMG). This compound is prepared by polycondensation of hexamethylenediamine and guanidine hydrochloride that yields weakly branched oligomers of a low molecular weight (up to $2 \mathrm{kDa}$, or a polymerization degree of 10-15) with amino or guanidine as terminal groups [27]. The pKa of protonated PHMG is 12.5, which makes it a polycation over a wide $\mathrm{pH}$ range (up to 12) [28], which is suitable for obtaining hydrophobic ion pairs with the drug. PHMG is known to be a potent antimicrobial agent: its $1 \mathrm{ppm}$ aqueous solution exhibits an antibacterial activity above $90 \%$ [27]. Secondly, PHMG has low toxicity to mammals as it has been shown that their enzymes efficiently decompose the compound (LD(50)), and PHMG was found to be at a concentration $600 \mathrm{mg} / \mathrm{kg}$ when administered as a single dose via the stomach tube [29]. 
To obtain healing and antimicrobial films, PHMG was used as complexes with chitosan [30] and polyvinyl alcohol [30,31].

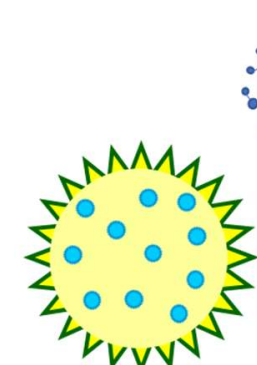

Carbocyanine dye in ethanol

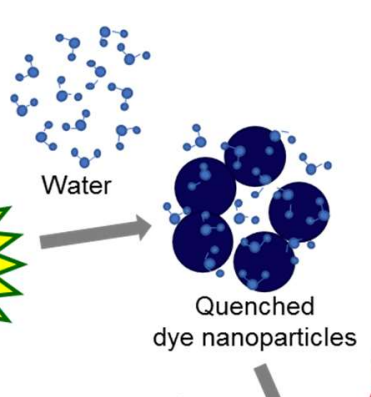

dye nanoparticles

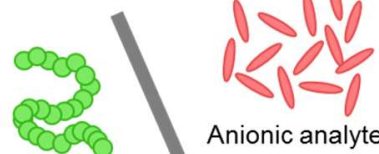
Anionic analyte

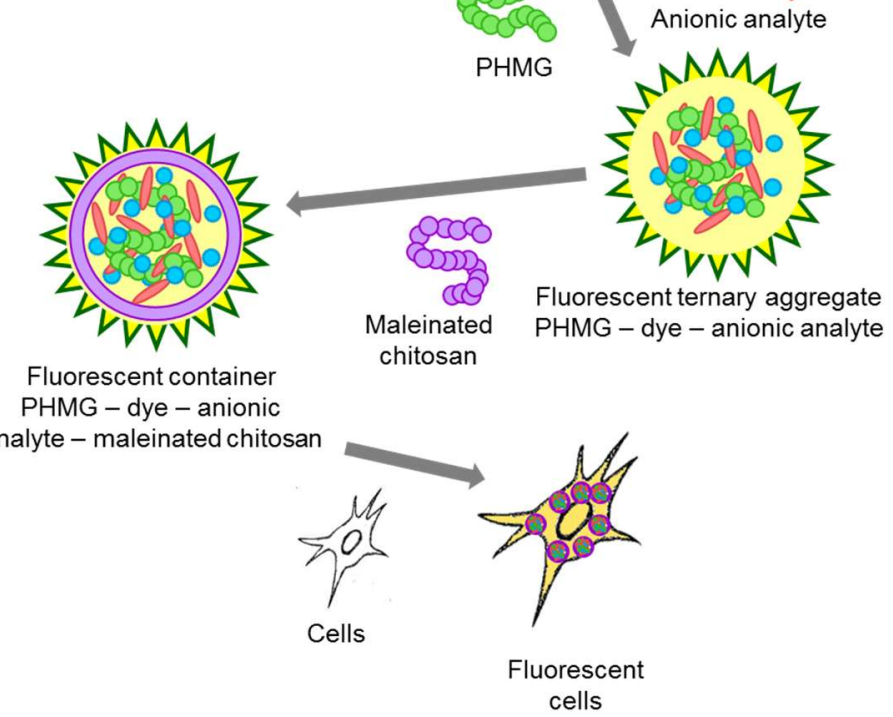

Scheme 2. A diagram of processes involved in obtaining the drug carrier (container) and its internalization by cells.

As a result, we have found that the chitosan containers containing the aggregates (drug-PHMG-carbocyanine dye) display a stable NIR fluorescent signal and can be uptaken by breast adenocarcinoma cells. In the literature, there are few examples of utilization of ion pairing for non-covalent labeling of a drug for its imaging-guided delivery $[7,8,19]$. An important feature of the suggested system is that the quantum yield is dependent on the fluorophore environment, namely the drug-counter-ion aggregate (in molecular form) exhibits strong fluorescence whereas the dye emits weakly when present in a nanoparticle form in an aqueous solution. This property is supposed to enable real-time monitoring of container destruction with the liberation of the drug. The use of fluorescence quenching on container decomposition [22] is an emerging trend in delivery systems. For instance, it was used in [8] but in that paper hydrophobic interactions were used rather than ionic self-assembly, which does not allow for binding the hydrophilic drugs. In papers [7,19], ionic self-assembly was utilized to bind the drug and the fluorophore, but the latter was not supposed to change its emission intensity upon container destruction. Overall, in this work we are using a unique combination of delivery system attributes.

\section{Results and Discussion}

\subsection{Aggregation Studies in Poly(hexamethylene guanidine)-Ceftriaxone-Dye System}

2.1.1. Quenching of the Dye Fluorescence in Water

Fluorescence enhancement in the ternary aggregates poly(hexamethylene guanidine)ceftriaxone-dye is only observed upon pre-quenching of the fluorescence of carbocyanine 
dye in water. The dye is emissive in organic solvents, but upon mixing with an excess of aqueous buffer it forms a colloidal solution of sphere-shaped nanoparticles [21], which absorb and emit very weakly (Figure 1).
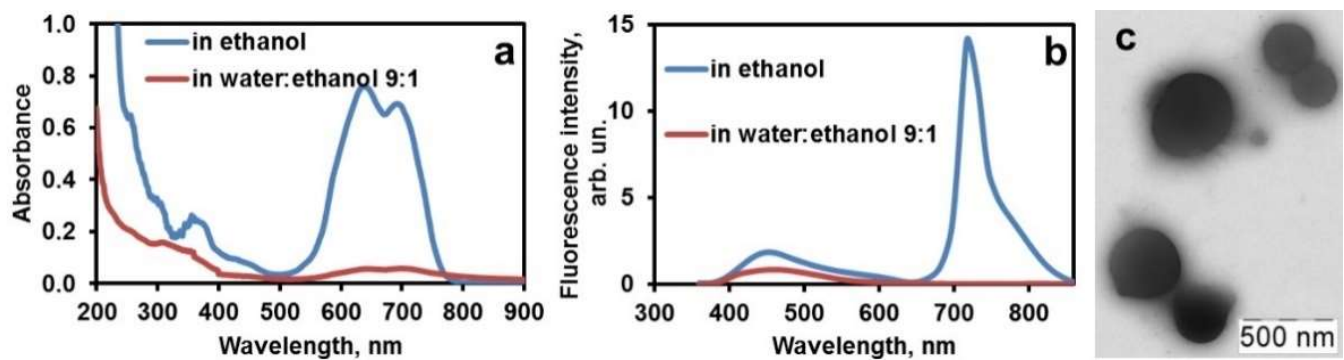

Figure 1. Absorbance (a) and fluorescence (b) spectra of ethanolic and aqueous solutions of $1 \mu \mathrm{M}$ dye; (c) TEM image of dye particles in water.

\subsubsection{Aggregation in the Ternary System PHMG-Ceftriaxone-Dye}

In binary systems (dye-ceftriaxone and dye-PHMG), no emission enhancement is observed. Ceftriaxone is negatively charged (at physiological pH of 7.4 used in study, its charge is -1 [32]), while PHMG exists as a polycation over a wide $\mathrm{pH}$ range [28]. Ceftriaxone and PHMG form ionic aggregates containing hydrophobic domains due to PHMG alkyl chains and are capable of solubilizing the carbocyanine dye nanoparticles, similar to the ceftriaxone-cetyltrimethylammonium (CTAB) system studied in paper [21]. Such solubilization is accompanied by a considerable fluorescence enhancement (the spectrum is shown in Figure 2b). Moreover, Rayleigh light scattering spectrum of the ternary system (Figure 2a) shows a notable difference between the spectra of the binary mixtures and single components, confirming the formation of ternary aggregate PHMG-ceftriaxone-dye.
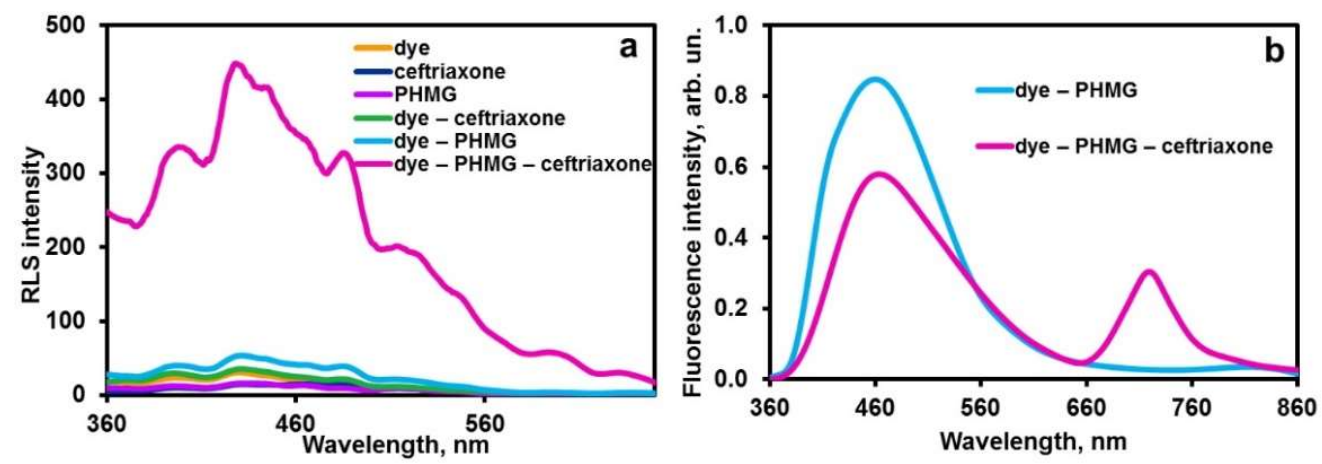

Figure 2. Rayleigh light scattering (a) and fluorescence (b) spectra of the system ceftriaxone-PHMGdye. Conditions: pH 7.4 (7 mM phosphate buffer), 2.2 mM PHMG, $2.8 \mu \mathrm{M}$ dye, $1.0 \mathrm{mM}$ ceftriaxone.

To estimate stability constant of the aggregate formed, the concentration dependences were studied for the system PHMG-ceftriaxone-dye (Figure 3). The emission intensities of binary systems (blue curves) are close to that of the background signal of the cell lacking a fluorophore, as measured by the NIR visualizer. On these grounds, the signal was postulated to be exclusively due to the emission of the ternary aggregates. As seen in Figure 3, NIR fluorescence intensities are represented as complex curves. However, their portions can be used for an estimation of the aggregation stability constant by using the Benesi-Hildebrand method [33]. The simplest complexation scheme can be written as the following equilibrium reaction:

$$
\mathrm{P}+\mathrm{C}+\mathrm{D}=\mathrm{PCD},
$$


where $\mathrm{P}$ is PHMG, $\mathrm{C}$ is ceftriaxone, D is dye, and the molar concentration of PHMG is calculated with respect to its monomer unit. The stability constant was calculated according to formula (see Appendix A for the details):

$$
K=\frac{[\mathrm{PCD}]}{[\mathrm{P}][\mathrm{C}][\mathrm{D}]}
$$
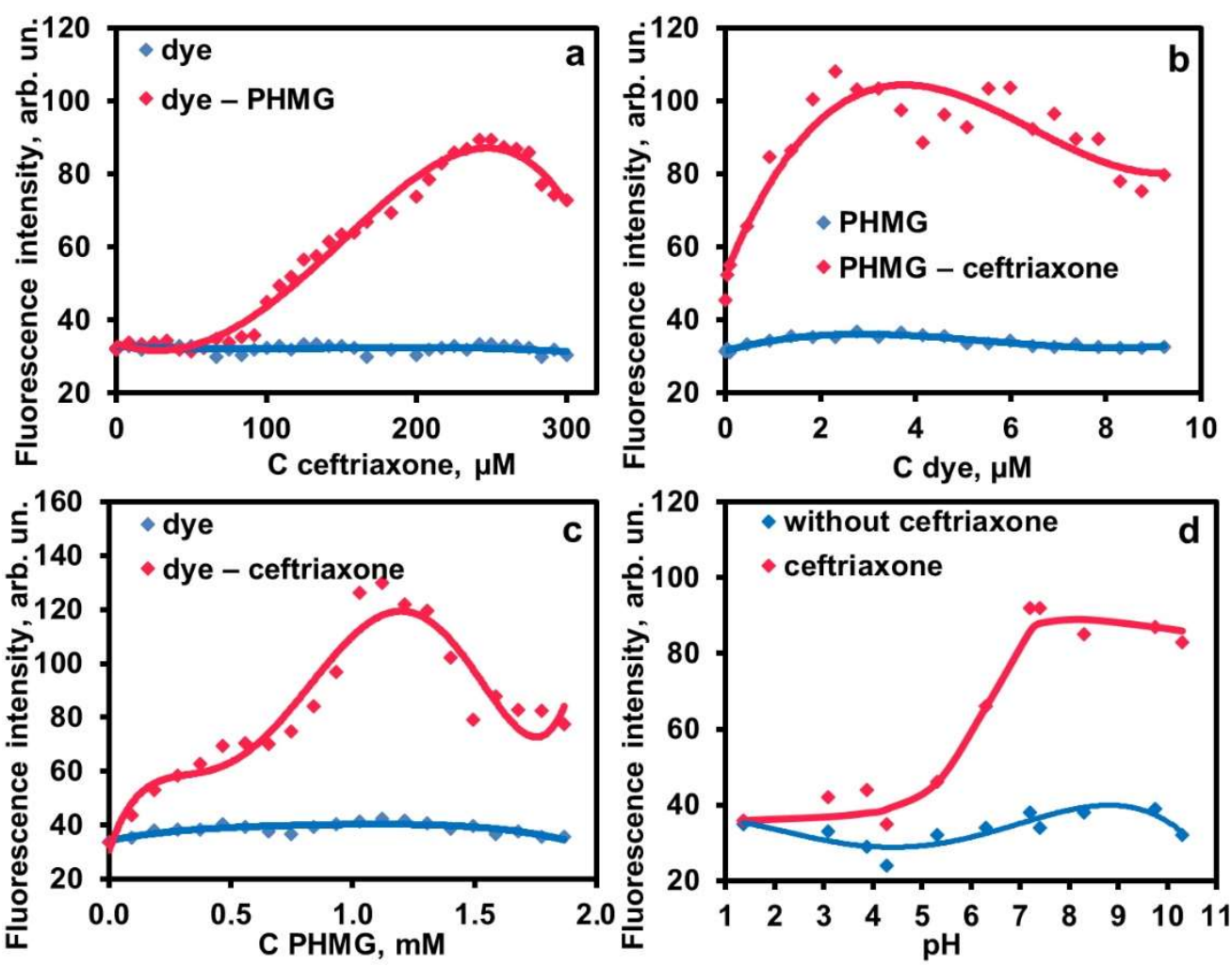

Figure 3. NIR fluorescence intensity for different concentrations of ceftriaxone (a), dye (b), PHMG (c) and $\mathrm{pH}(\mathrm{d})$. General conditions: $\mathrm{pH} 7.4$ (7 mM phosphate buffer), 2.2 mM PHMG, $2.8 \mu \mathrm{M}$ dye, 1 $\mathrm{mM}$ ceftriaxone. In varying $\mathrm{pH}$, the following buffers were used in $7 \mathrm{mM}$ concentrations (by anion): borate ( $\mathrm{pH}$ 9-10), phosphate ( $\mathrm{pH} 5.5-8.1$ ), acetate ( $\mathrm{pH} 3.5-5.0)$, and $\mathrm{HCl}(\mathrm{pH} 1.8-2.8)$.

The obtained values of the constant for PHMG and CTAB as counter-ions determined from two different curves (Table 1) should only be considered as rough estimates due to the complexity of the system. The value of $\sim 10^{6}$ (or about $10^{4}$ if recalculated for two interacting particles) is comparable by the order of magnitude with the stability of ion pairs of an organic cation (celiprolol) with chloride ion $\left(5 \times 10^{5}\right.$ [34]) or an organic anion citrate(3-) with $\mathrm{Ca}^{2+}$ cation $\left(1.5 \times 10^{3}[35]\right)$, which confirms moderate stability of the aggregates and their ability to decompose on dilution. The stability of the PHMG aggregate is five-fold higher than that of CTAB, most probably due to the polymeric nature of PHMG. 
Table 1. Estimation of the stability constants of PHMG-ceftriaxone-dye and CTAB-ceftriaxone-dye aggregates by the Benesi-Hildebrand method.

\begin{tabular}{|c|c|c|c|c|c|c|c|c|}
\hline \multirow{2}{*}{$\begin{array}{l}\text { Counter-Ion } \\
(\mathbf{P})\end{array}$} & \multicolumn{2}{|c|}{$\begin{array}{l}\text { Concentration (or Its Range), } \\
\mathrm{mM} \text {, Used in Calculations }\end{array}$} & \multicolumn{2}{|c|}{$\begin{array}{l}\text { Regression Coefficients } \\
( \pm \mathrm{SD}) \text { for } y=A+B x\end{array}$} & \multirow{2}{*}{$\begin{array}{l}\text { Number of } \\
\text { Points }\end{array}$} & \multirow{2}{*}{$\begin{array}{l}\text { Stablitiy } \\
\text { Constant } K \\
\quad \pm \text { SD }\end{array}$} & \multicolumn{2}{|c|}{$\begin{array}{l}\text { Coefficient of } \\
\text { Determination for the } \\
\text { Regression, } R^{2}\end{array}$} \\
\hline & Counter-Ion & Ceftriaxone & $A$ * & $B$ * & & & 1:1 & $1: 2 * *$ \\
\hline PHMG & $0.4-1.2$ & 1.0 & $\begin{array}{c}(5.1 \pm 0.8) \times \\
10^{-3}\end{array}$ & $\begin{array}{c}(4.3 \pm 0.6) \times \\
10^{-6}\end{array}$ & 9 & $\begin{array}{c}(1.2 \pm 0.2) \times \\
10^{6}\end{array}$ & 0.93 & 0.86 \\
\hline PHMG & 2.2 & $0.10-0.25$ & $\begin{array}{c}(4.1 \pm 0.3) \times \\
10^{-3}\end{array}$ & $\begin{array}{l}(1.76 \pm 0.04) \\
\quad \times 10^{-6}\end{array}$ & 17 & $\begin{array}{c}(1.1 \pm 0.1) \times \\
10^{6}\end{array}$ & 0.99 & 0.97 \\
\hline CTAB & $0.02-0.85$ & 1.7 & $\begin{array}{c}(1.4 \pm 0.2) \times \\
10^{-3}\end{array}$ & $\begin{array}{c}(2.4 \pm 0.3) \times \\
10^{-6}\end{array}$ & 7 & $\begin{array}{c}(3.4 \pm 0.5) \times \\
10^{5}\end{array}$ & 0.96 & 0.80 \\
\hline CTAB & 0.085 & $0.015-1.5$ & $\begin{array}{c}(2.0 \pm 0.1) \times \\
10^{-2}\end{array}$ & $\begin{array}{c}(3.6 \pm 0.7) \times \\
10^{-7}\end{array}$ & 7 & $\begin{array}{c}(6.7 \pm 0.7) \times \\
10^{5}\end{array}$ & 0.97 & 0.89 \\
\hline
\end{tabular}

${ }^{*} A=\frac{1}{\varepsilon \cdot \mathcal{C}(\mathrm{D})}$ and $B=\frac{1}{\varepsilon \cdot \mathcal{C}(\mathrm{D}) \cdot K \cdot \mathcal{c}(\mathrm{C})}\left(\right.$ or $\left.B=\frac{1}{\varepsilon \cdot \mathcal{C}(\mathrm{D}) \cdot K \cdot(\mathrm{P})}\right)$, where $c$ is total concentrations of the counter-ion (P), ceftriaxone I, and dye (D); $\varepsilon=I /[\mathrm{PCD}] ; \mathrm{I}$ is fluorescence intensity. ${ }^{* *}$ For the composition of the aggregate of $\mathrm{PC}_{2} \mathrm{D}$ when $\mathrm{C}$ is varied, and $\mathrm{P}_{2} \mathrm{CD}$ when $\mathrm{P}$ is varied (see Appendix A for the details).

\subsection{Encapsulation of Ternary Aggregates in Chitosan Containers}

\subsubsection{Anated Chitosans Used in Developing Containers}

To assemble delivery vehicle, the ternary aggregates of ceftriaxone-PHMG-dye were encapsulated into biocompatible containers, which have been prepared using the common types of anionic chitosan, namely maleated and carboxymethylated, obtained according to known methods [36,37]. Carboxymethylation of chitosan with sodium chloroacetate was supposed to occur predominantly at O-6 [38], whereas the reaction with maleic anhydride leads to carboxymethylation of the amino group [39]. Additionally, sulfated maleated chitosan was obtained from maleated chitosan by treatment with metabisulfite (a source of hydrosulfite) as a result of reaction of the sulfonic acid group with the maleate double bond [37].

The ceftriaxone-PHMG-dye-chitosan complexes were obtained by precipitation from the mixture of the aqueous solutions of the components at physiological pH 7.4 (phosphate buffer).

\subsubsection{Chitosan Cross-Linking}

Dialysis studies (data not shown) indicated that uncrosslinked quaternary complexes decompose in less than $1 \mathrm{~h}$ and become non-fluorescent. To overcome that disadvantage, the chitosan containers were cross-linked with aldehydes, which are known to increase stability of containers [40]. Glutaraldehyde was among the most efficient cross-linkers [41]. We used formaldehyde, glyoxal, and glutaraldehyde according to the following procedure. The aldehyde solution was added to the ultrasound-pretreated suspension of containers at $\mathrm{pH} 7.4$ and left for a day at room temperature. The resulting suspension was sonicated following by fluorescence monitoring. Only the containers, which have been obtained using glutaraldehyde, showed measurable fluorescence (Figure 4). Since this aldehyde has been found to be a good cross-linking reagent for carboxymethylated and sulfated maleated chitosan, it was considered as a potent cross-linker in further work. 


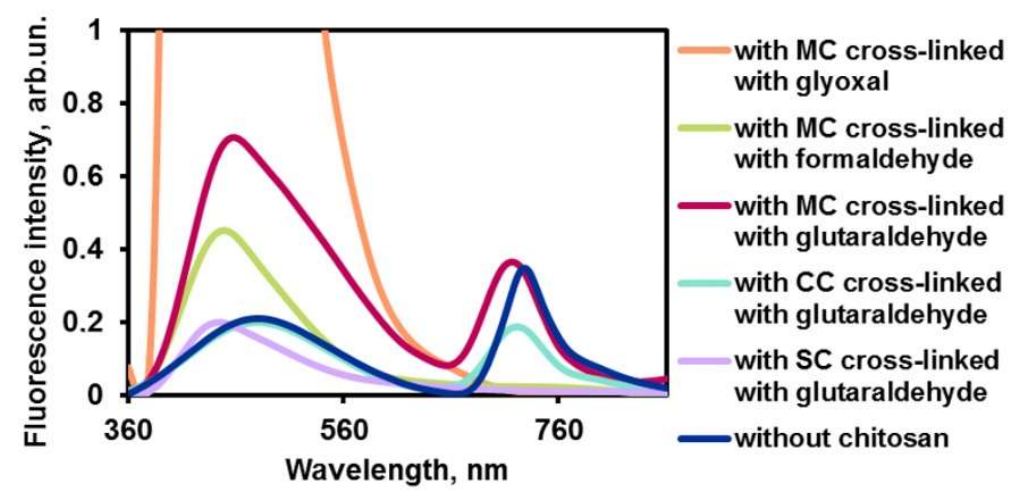

Figure 4. Fluorescence spectra of aggregates dye-ceftriaxone-PHMG-chitosan with various crosslinkers and chitosans: maleated (MC), carboxymethylated (CC), and sulfated (SC).

\subsection{Characterization of Poly(hexamethylene guanidine)-Ceftriaxone-Dye-Maleated Chitosan Containers}

\subsubsection{Morphology and Size of Container Particles}

TEM images showed the cross-linked chitosan containers to be nanoparticles of about $70 \mathrm{~nm}$ in diameter in the form of chains and conglomerates (Figure 5a). The TEM image of similar containers obtained without ceftriaxone indicated that the nanoparticles are somewhat smaller (40-50 nm), but otherwise their morphology is similar to that of the containers containing ceftriaxone (Figure S3 in Supplementary Materials). In the absence of chitosan, the ternary aggregates represent 100-300 $\mathrm{nm}$ sphere-shaped particles with an electron-dense core, similar to the particles of the dye (Figure 1c).

a
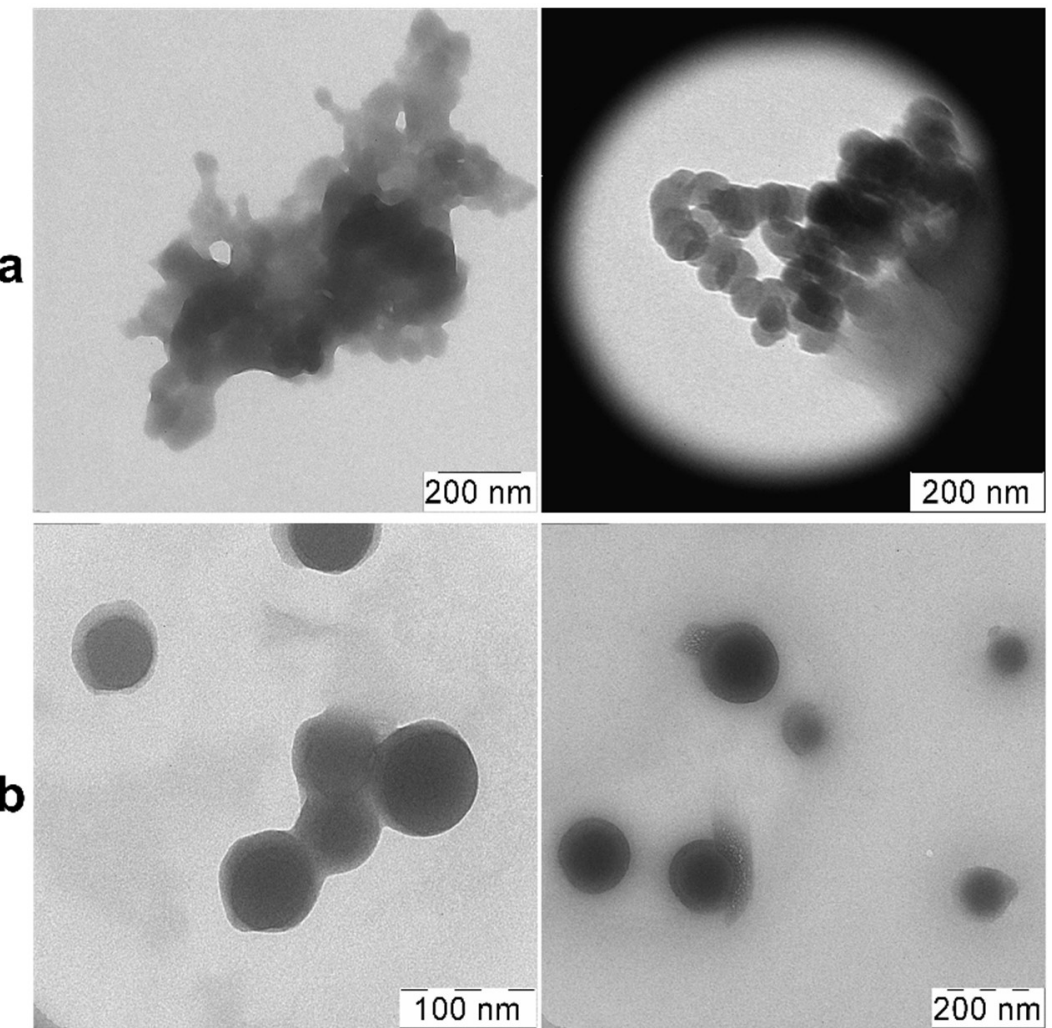

Figure 5. Transmission electron microscope images of containers chitosan-PHMG-ceftriaxone-dye (a) and ternary aggregates PHMG-ceftriaxone-dye (b). The solutions were evaporated to dryness on a TEM copper grid. The nanoparticle diameter is (a) 47-109 $\mathrm{nm}$ with an average value of $67 \mathrm{~nm}$ and (b) 117-283 nm with an average value of $200 \mathrm{~nm}$ (from 39 measurements in a number of images). 
The particle size of cross-linked systems estimated by dynamic light scattering (DLS) technique (Table 2) has shown to be predictably increased for chitosan-PHMG compared to that for the quaternary system PHMG-ceftriaxone-dye-chitosan. A slight reduction in size observed for maleated chitosan in contrast to that for chitosan-PHMG can be explained by the polyelectrolyte coil shrinking upon interaction of anionic chitosan with PHMG cations. According to DLS data, the obtained containers are polydispersed in aqueous solution due to aggregation processes having particle size varying from the smallest aggregates of 200-300 nm in diameter (by the number distribution, Table 2) to the largest ones of micron size (by the intensity distribution, Table 2). Particles of those sizes are visible in TEM. The complete size distributions provided by Zetasizer software are given in Supplementary Materials (Figure S1).

Table 2. Particle sizes obtained by dynamic light scattering technique in $7 \mathrm{mM}$ phosphate buffer solution ( $\mathrm{pH} 7.4)$.

\begin{tabular}{cccc}
\hline \multirow{2}{*}{ Scheme } & \multicolumn{3}{c}{ Mean Particle Size, nm } \\
\cline { 2 - 4 } & by Intensity & by Volume & by Number \\
\hline Chitosan (maleated) & 548 & 712 & 66 \\
Chitosan-PHMG & 434 & 437 & 265 \\
Chitosan-PHMG-ceftriaxone & 1065 & 1267 & 253 \\
Chitosan-PHMG-dye & 1105 & 1238 & 207 \\
Chitosan-PHMG-ceftriaxone-dye & 1190 & 1426 & 319 \\
\hline
\end{tabular}

\subsubsection{Zeta Potentials}

Since the positive charge of the carrier can lead to more efficient uptake by cells, the molar ratio of PHMG to ceftriaxone was maintained at 2:1. The zeta potentials of particles for the ceftriaxone-PHMG-dye-chitosan system are shown in Figure 6. The dye nanoparticles have no intrinsic charge $(\xi=+1 \mathrm{mV})$, but they acquire it by adsorbing PHMG $(\xi=+23 \mathrm{mV})$. The ternary aggregates PHMG-ceftriaxone-dye are also positively charged $(+17 \mathrm{mV})$ in the excess of PHMG, which allows them to interact with anionic chitosan. Among all crosslinked chitosan-containing particles, which retain the positive charge imparted to them by PHMG $(+24 \ldots+28 \mathrm{mV})$, the target containers chitosanceftriaxone-PHMG-dye hold out the prospect of efficient endocytosis. The obtained values also indicate that the nanoparticles can be stable on storage. In principle, the charge can be controlled by changing the PHMG:ceftriaxone ratio.

\subsubsection{FT-IR Spectra}

Unmodified chitosan (Figure 7a) shows major peaks at 3280/3360, 2860-2930, 1660, $1593,1423,1377$, and 1000-1150 $\mathrm{cm}^{-1}$, corresponding to $v(\mathrm{OH} / \mathrm{NH}), v(\mathrm{CH}), v(\mathrm{C}=\mathrm{O})$, $\delta\left(\mathrm{NH}_{2}\right)$, two $\delta(\mathrm{COH})$, and mixed $v(\mathrm{C}-\mathrm{O}-\mathrm{C} / \mathrm{C}-\mathrm{OH})$ vibrations, respectively [42]. After maleation and cross-linking (Figure $7 \mathrm{~b})$, the chitosan peaks of $\delta\left(\mathrm{NH}_{2}\right)$ and $v(\mathrm{C}=\mathrm{O})$ at 1593 and $1660 \mathrm{~cm}^{-1}$ are shifted to spectral regions of lower energy at 1555 and $1633 \mathrm{~cm}^{-1}$, respectively, which agrees with the data described in [43] wherein $22-36-\mathrm{cm}^{-1}$ shifts of these bands were also observed. A peak from remaining acetamide group of chitosan $v(\mathrm{C}=\mathrm{O})$ is present at $1656 \mathrm{~cm}^{-1}$. The $1633 \mathrm{~cm}^{-1}$ peak also corresponds to the amide group $\delta\left(\mathrm{NH}_{2}\right)$ of chitosan, which resulted from cross-linking with aldehydes [44]. A shift of the $\delta(\mathrm{COH})$ peak was detected from 1377 to $1356 \mathrm{~cm}^{-1}$ upon maleation, and an increase in intensity of the $\delta(\mathrm{COH})$ peak at $1423 \mathrm{~cm}^{-1}$ was observed. Appearance of the peak at $1746 \mathrm{~cm}^{-1}$ has confirmed the formation of carboxylic group due to maleation of chitosan, which was found to be similar to that for carboxymethylated chitosan (Figure S2 in Supplementary Materials). 


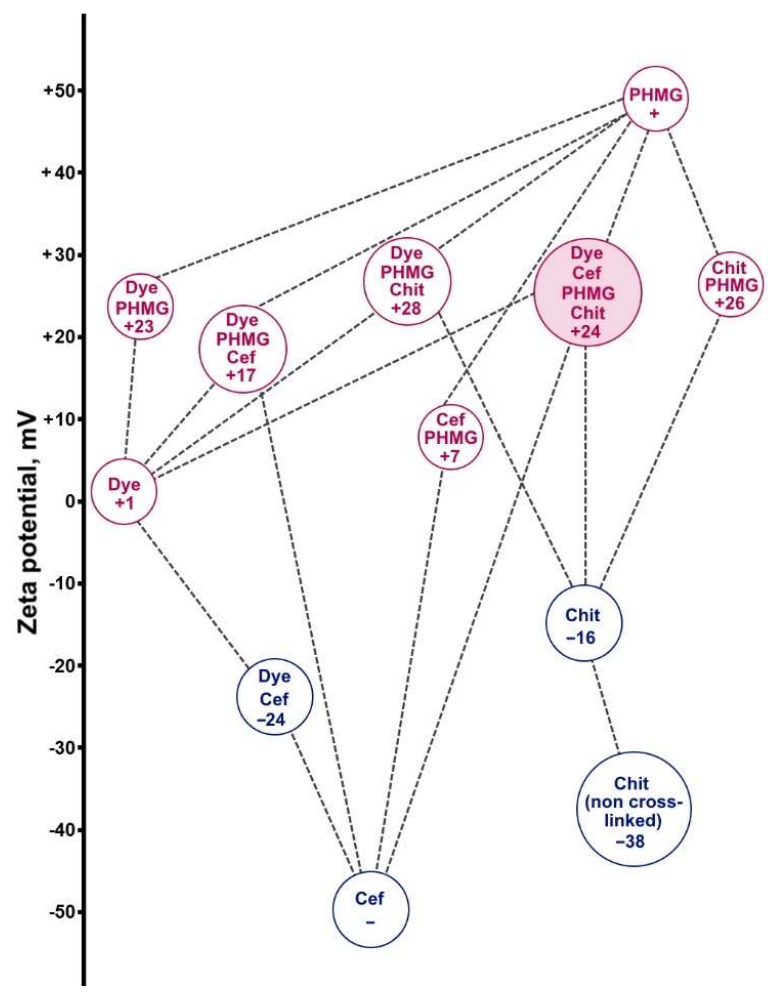

Figure 6. Zeta potentials of particles in the systems, containing maleated chitosan (Chit; all Chit-containing systems were cross-linked with glutaraldehyde, if not labeled otherwise); poly(hexamethyleneguanidine hydrochloride) (PHMG), ceftriaxone (Cef) and dye, in $7 \mathrm{mM}$ phosphate buffer ( $\mathrm{pH}$ 7.4). Concentration of components (polymers-by monomer unit): $1.4 \mathrm{mM}$ Chit, 2.2 mM PHMG, 1.0 mM Cef, 2.8 MM dye. Soluble compounds, Cef and PHMG, are marked with "-" and "+", respectively.

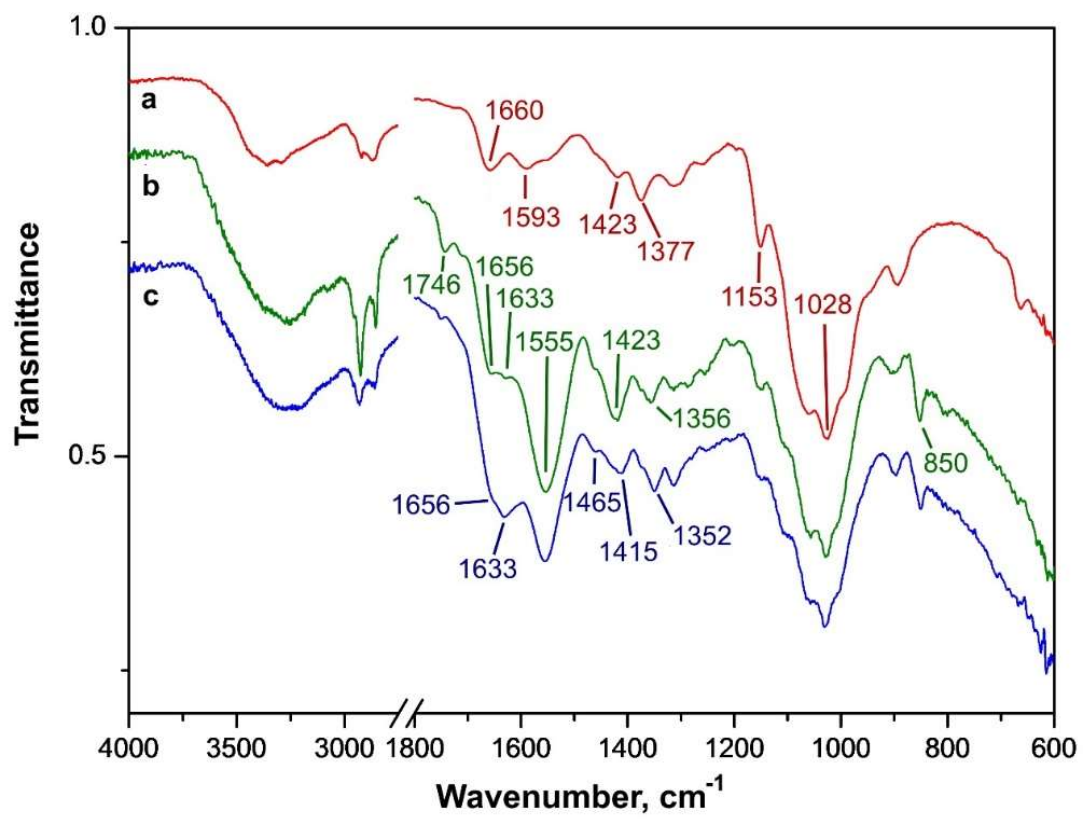

Figure 7. FT-IR spectra of solid samples of chitosan (a), maleated chitosan (b) and containers maleated chitosan-PHMG-ceftriaxone-dye (c).

The mentioned above peaks are also present in the maleated chitosan containers sample (Figure 7c). The absorbance of containers is increased due to the presence of 
ceftriaxone and PHMG. The FT-IR spectra for the containers show absorption at 1352, $1415,1465,1633 \mathrm{~cm}^{-1}$ corresponding to the unbound ceftriaxone peaks at 1370,1395, 1500, $1655 \mathrm{~cm}^{-1}$ [45]. Similarly to the intense $\delta(\mathrm{NH})$ band of unbound PHMG at $1635 \mathrm{~cm}^{-1}$ and a $\delta\left(\mathrm{CH}_{2}\right)$ peak at $1460 \mathrm{~cm}^{-1}$ reported in paper [46], we detected the peaks at 1633 and $1465 \mathrm{~cm}^{-1}$, respectively, in the container spectrum (Figure 7c). There was no band specific of dye in the IR spectra due to its low amount in the containers ( $0.2 \%$ mass).

The IR spectra of other functionalized chitosans confirming their chemical modifications are given in Supplementary Materials (Figure S2).

\subsubsection{Kinetic Stability}

The fluorescence spectra of container suspension, which has been stored at $4{ }^{\circ} \mathrm{C}$, were recorded at one-week intervals. The stability of the NIR signal has been observed for at least a week (Figure 8). A similar result was obtained by Mendes et al., who obtained chitosan nanoparticle stability during a week under the same conditions [47]. The other containers were stable up to 14 days, their size and surface charge changing slightly during that period [48].

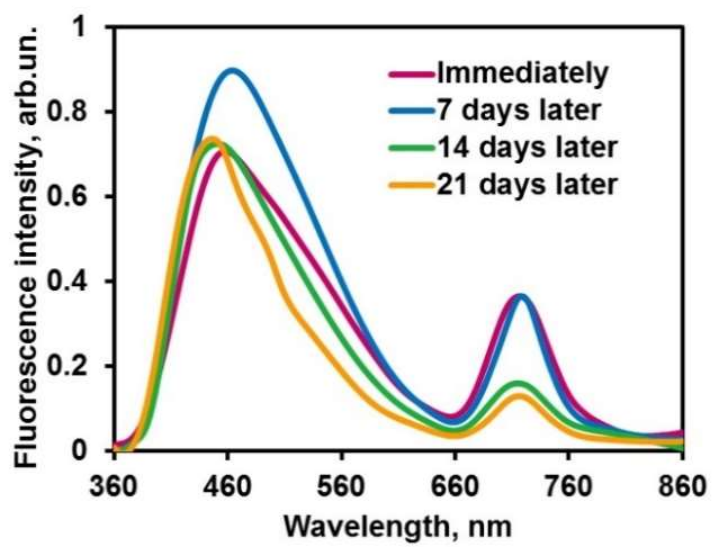

Figure 8. Effect of storage time on the emission spectra of the aqueous supension of maleated chitosan-PHMG-ceftriaxone-dye containers (excited at $345 \mathrm{~nm}$ ).

\subsubsection{Drug Loading Capacity}

Drug loading capacity (DLC) was estimated as follows:

$$
\mathrm{DLC}=\frac{c(\text { initial })-c(\text { solution })}{c(\text { container })} 100 \%
$$

Here, $c$ (container) is the mass concentration of container material, $c$ (initial) is the mass concentration of ceftriaxone introduced in the solution during the preparation of the containers, and $c$ (solution) is the concentration of ceftriaxone in the supernatant obtained after centrifugation of the cross-linked container suspension in PBS. The following formula was used: $c$ (solution) $=A / \varepsilon \times f$, where $A$ is absorbance at $241 \mathrm{~nm}, \varepsilon$ is molar absorption coefficient of ceftriaxone $\left(2.4 \times 10^{4}\right)$, and $f$ is dilution factor $(f=125)$. The spectrum was recorded with respect to the blank solution of container without ceftriaxone. The same calculation was performed using a ceftriaxone absorption band at $278 \mathrm{~nm}$ and the results were averaged to obtain the value of $c$ (solution) $=0.038 \mathrm{mg} / \mathrm{mL}$. Given $c$ (initial) for ceftriaxone was $1 \mathrm{mM}(0.66 \mathrm{mg} / \mathrm{mL}), c$ (solution $)=0.62 \mathrm{mg} / \mathrm{mL}$ and concentration of the suspension was $0.54 \mathrm{mg} / \mathrm{mL}$ with respect to chitosan, the estimate of ceftriaxone loading was $7 \%$ by mass. The obtained value is moderate but it is sufficient for the proofof-concept study. 


\subsection{Cytotoxicity Measurements}

According to the ISO 10993-5 standard, the threshold of cytotoxic biomaterial is below $70-80 \%$ cell viability [49]. Cytotoxicity test by WST-1 assay (Figure 9) showed that $70-80 \%$ cell viability following $24 \mathrm{~h}$ of exposure to chitosan containers was observed at the container concentration below $0.2 \mathrm{mg} / \mathrm{mL}$, which is sufficient for in vitro or in vivo imaging. According to the tests of container components, the main contribution to the final formulation cytotoxicity was made by PHMG: this compound reduced the cell viability stronger than the containers. These data are in a line with literature [50]. Aqueous ceftriaxone solutions at the concentrations of up to $0.5 \mathrm{mM}$ have shown low cytotoxicity, which is consistent with the literature [51]. The solutions of chitosan and dye exhibited cytotoxicity, which appeared to be less or comparative to that of the containers. Overall, we found the suggested containers were non-toxic, as was observed in papers $[52,53]$ for the other carboxymethylated chitosan particles.
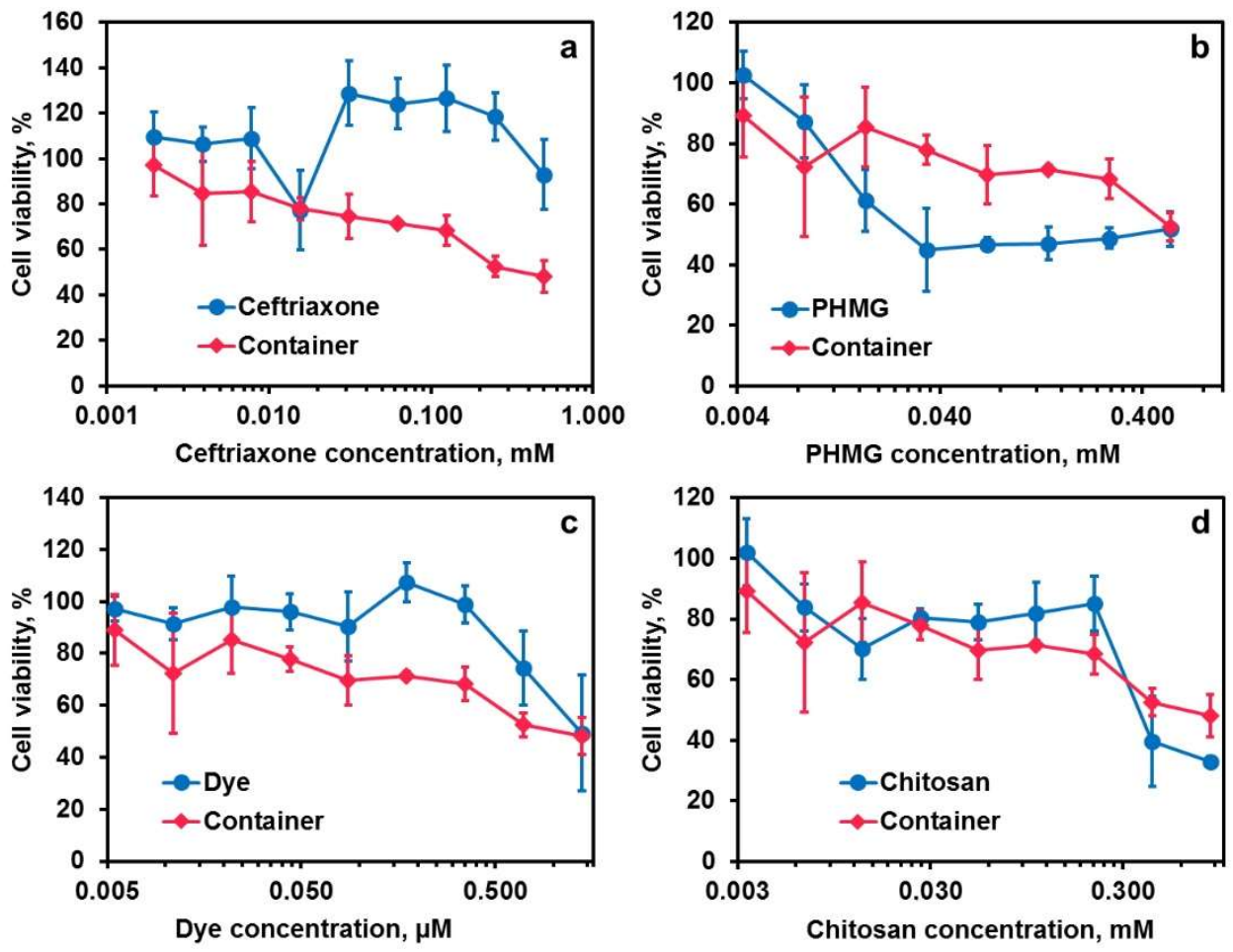

Figure 9. Cytotoxic activity of the chitosan containers with PHMG-ceftriaxone-dye (red lines) shown together with the graphs for free ceftriaxone alone (a), free PHMG alone (b), free dye alone (c) and free chitosan alone (d) on the MCF7 cell line after $24 \mathrm{~h}$ of incubation. Each value represents the mean $\pm \operatorname{SD}(n=3)$.

\subsection{Chitosan Containers Uptake by Breast Adenocarcinoma Cells}

The cells were incubated with the chitosan containers in confocal microscopy plates ( $40 \mathrm{~min}, 37^{\circ} \mathrm{C}$ ) with the subsequent fixation with formaldehyde. For these experiments, all chitosans used for obtaining containers were labeled with Rhodamine isothiocyanate [54]. The conditions of fluorescence measurement in CLSM are given in Table 3.

Table 3. Modes of confocal laser scanning microscope measurements.

\begin{tabular}{ccc}
\hline Excitation laser wavelength, nm & 515 & 635 \\
Registration wavelength range, nm & $540-590$ (channel 1) & $655-755$ \\
Species to be observed & $\begin{array}{c}\text { Rhodamine-labeled } \\
\text { chitosan }\end{array}$ & Dye \\
\hline
\end{tabular}


As shown in Figure 10, NIR fluorescence of both dye and Rhodamine (which was used as a label for chitosan), is visible in the cytoplasm and nucleus of the cell. The container components (dye, ceftriaxone, and chitosan) are capable of entering the cells separately (Figure S4 in Supplementary Materials). The emission intensities of Rhodamine that is proportional to the amount of chitosan (channel 1) are approximately equal in all systems, suggesting that chitosan particles can enter the cell either being attached to the drug or in the free form.

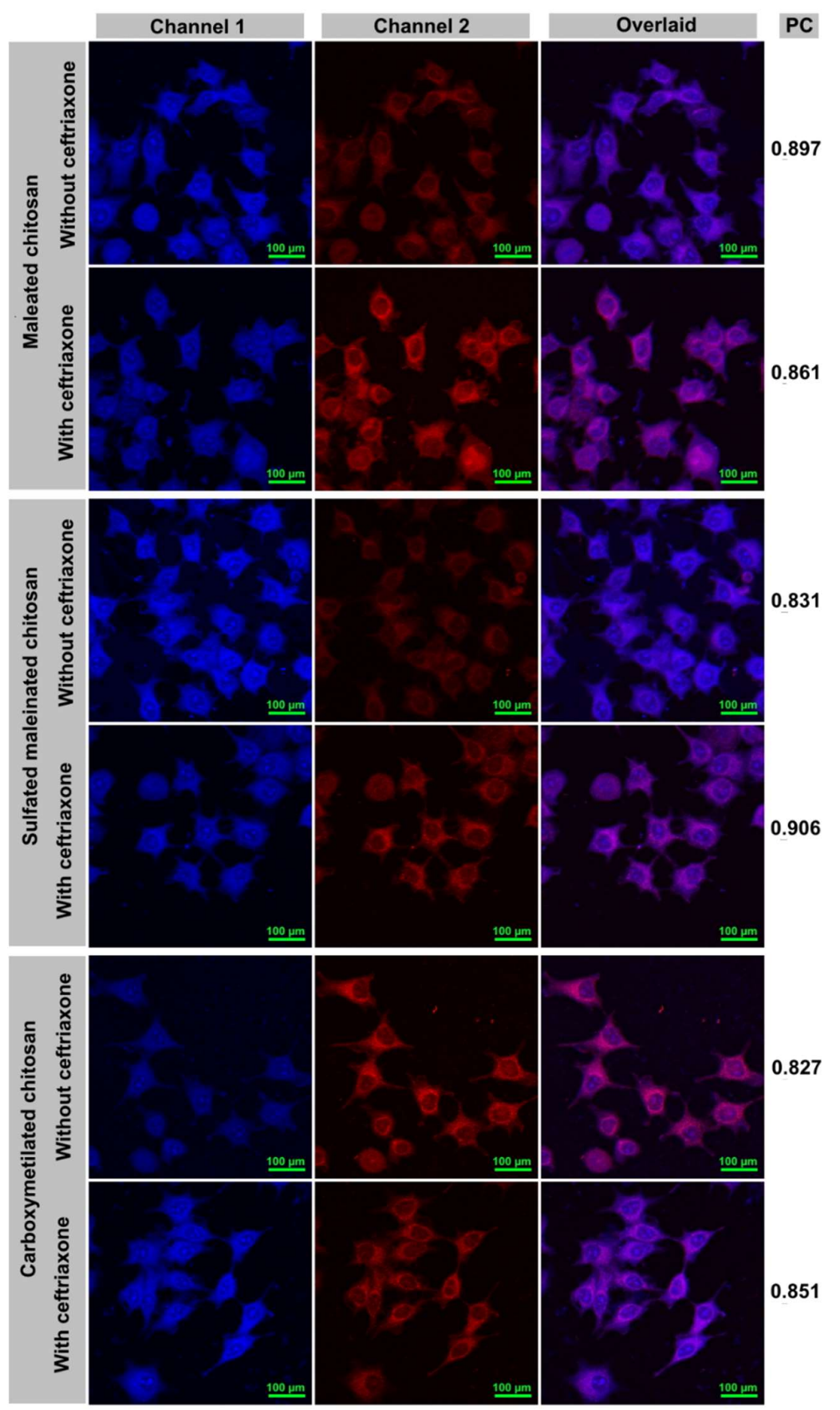

Figure 10. CLSM images of the aggregates dye-PHMG and dye-ceftriaxone-PHMG encapsulated into different chitosan types endocytosed into cells. For each sample, images from left to right show: channel $1\left(\lambda_{\mathrm{ex}}=515 \mathrm{~nm}\right)$, channel $2\left(\lambda_{\mathrm{ex}}=635 \mathrm{~nm}\right)$, and the overlay of the two images. PC: pearson's colocalization coefficient. 
In this study, it is pertinent to address the problem of understanding whether the fluorescence of the container delivered into the cells is caused by incorporation of the nanocarrier or is a result of a free dye uptake. Given there is a difference in the intensities of the signals for the loaded and non-loaded carriers, similar to that described in literature [55,56], we can assume that the cells uptake the container. To test whether the NIR signal (channel 2) belongs to the remaining intact quaternary container dye-PHMG-ceftriaxone-chitosan, we have calculated the colocalization coefficients of both dye (channel 2) and chitosan (channel 1). The data obtained showed that they are in the range of 0.83-0.91 (Figure 10), which confirms that in the cell, the dye and chitosan are located in the same area (probably in the form of containers).

Besides, we have compared the NIR intensities (channel 2) for the containers with ceftriaxone and those without it (Figure 10). The latter, which presented less bright emission, indicated the lack of ceftriaxone-PHMG aggregates, which could solubilize the dye, thus causing NIR emission enhancement (channel 2; a quantitative comparison of intensities is shown in Figure 11). For carboxymethylated chitosan, there was no spectral intensity differences observed for the system containing the drug and without one. Overall, these data confirm that fluorescence manifested by the cells is caused by entire containers rather than their individual components. We suggested that ceftriaxone is actually delivered to the cells in the form of a ternary aggregate encapsulated in maleated chitosan.

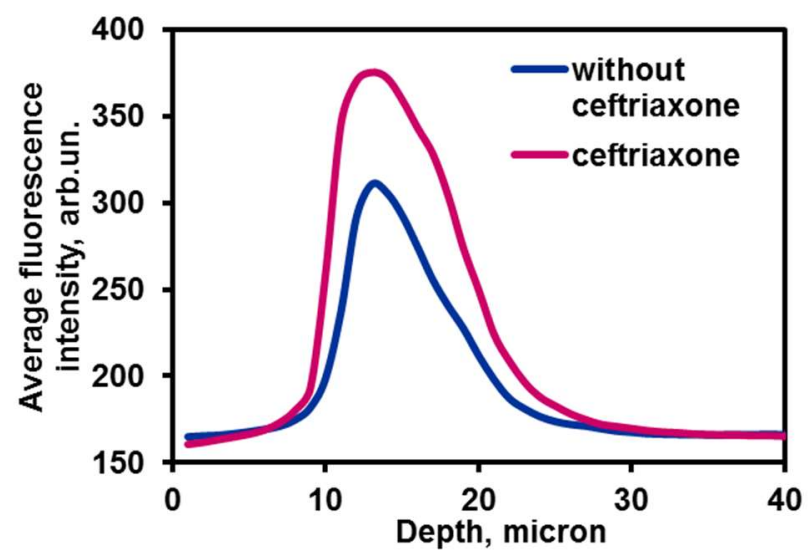

Figure 11. Intensity of channel 2 for the cell samples incubated with maleated chitosan containers as a function of depth obtained by CLSM Z-stack profiling.

\section{Materials and Methods}

\subsection{Compounds}

The carbocyanine dye was synthesized according to [21] (see Supplementary Materials). Chitosan obtained from Bioprogress (Shchelkovo, Russia) had a viscosity average molecular weight of $300 \mathrm{kDa}$, polydispersity index of 0.65 and deacetylation degree of $85 \%$. PHMG with an average polymerization degree of 11 was received from Institute of Ecotechnologies (Moscow, Russia). Other reactants were purchased from Sigma-Aldrich (Taufkirchen, Germany) and used as received. Acetate ( $\mathrm{pH} 3-5)$, phosphate ( $\mathrm{pH}$ 6-8), and borate ( $\mathrm{pH} 9-10$ ) buffer solutions were used to maintain $\mathrm{pH}$ values. Phosphate buffered saline (PBS) was prepared by dissolving $1.6 \mathrm{~g} \mathrm{NaCl}, 0.04 \mathrm{~g} \mathrm{KCl}, 0.288 \mathrm{~g} \mathrm{Na}_{2} \mathrm{HPO}_{4}$ and 0.049 $\mathrm{g} \mathrm{KH}_{2} \mathrm{PO}_{4}$ in $100 \mathrm{~mL}$ of water. Millipore water $(18 \mathrm{~m} \Omega \cdot \mathrm{cm})$ or $95 \%$ ethanol (Bryntsalov-A, Moscow, Russia) were used in preparing solutions.

\subsection{Instrumentation}

Fluorescence and Rayleigh light scattering (RLS) spectra were obtained using a "Fluorat-02 Panorama" spectrofluorometer (Lumex, Saint Petersburg, Russia) in 1-cm length quartz cells. The UV-vis absorption spectra were recorded on SF-102 spectrophotometer (Interphotophysica, Moscow, Russia) in 1-cm quartz cells. Near IR fluorescence 
in 96-well plates (Thermo Scientific Nunc F96 MicroWell, white, cat. No 136101, Thermo Fisher Scientific, Waltham, MA, USA) was registered using a setup [21] containing an LED source (eleven 3-Wt red LEDs, emission maximum $660 \mathrm{~nm}$; Minifermer, Moscow, Russia) and an NIR digital camera-modernized Nikon D80 (Nikon, Tokyo, Japan) with a filter transmitting light with wavelengths above $700 \mathrm{~nm}$. Particle size distribution by the dynamic light scattering (DLS) technique and zeta-potentials were measured with a Zetasizer Nano ZS (Malvern Panalytical, Malvern, UK). FT-IR spectra were obtained using a Tensor 27 (Bruker, Bremen, Germany) spectrometer. Electronic micrographs in a transmission electron microscope (TEM) were obtained by applying the investigated solution onto a standard TEM copper grid covered with Formvar film (thickness $50 \mathrm{~nm}$ ), drying on air, and imaging with a LEO 912AB OMEGA transmission electron microscope (Carl Zeiss, Oberkochen, Germany) with accelerating voltage $100 \mathrm{kV}$. Fluorescence images were obtained by confocal laser scanning microscope (CLSM) Olympus FluoView FV1000 (Olympus, Tokyo, Japan) equipped with a spectral version scan unit based on a motorized inverted microscope Olympus IX82 (Olympus, Tokyo, Japan). The $40 \times$ objective lens with a numerical aperture of 0.9 was used in the measurements. A Sonopuls ultrasonic homogenizer (Bandelin, Berlin, Germany) was used to disperse suspensions. Dialysis tubes (Pur-A-Lyzer Maxi 3500 or Midi 3500, MWCO 3.5 kDa, Sigma, Taufkirchen, Germany) were used for dialysis.

\subsection{Preparation of Maleated Chitosan}

Maleated chitosan was prepared according to [37]. A total of $0.90 \mathrm{~g}$ of chitosan was dissolved in $90 \mathrm{~mL}$ of $0.2 \mathrm{M}$ acetate buffer ( $\mathrm{pH}$ 5.0) with stirring for a few hours. After complete dissolution, $1.8 \mathrm{~mL}$ of $3 \mathrm{M}$ maleic anhydride in dioxane was added, and the obtained precipitate was dissolved by adjusting the $\mathrm{pH}$ value to 8.7 with $9.5 \mathrm{~mL}$ of $3 \mathrm{M} \mathrm{KOH}$ solution. Next, another $1.8 \mathrm{~mL}$ portion of maleic anhydride was added to the resulting solution and the product was neutralized with $3 \mathrm{M} \mathrm{KOH}$ to $\mathrm{pH} 8$. The final concentration of chitosan in solution was $0.045 \mathrm{M}$ by repeating unit.

The amount of free amino groups remaining after maleation was determined by using the trinitrobenzene sulfonic acid (TNBS) method [57]. Briefly, aliquots containing 0.5-1.0 mmol chitosan (by repeating unit) or 0.1-1.0 mmol L-leucine as standard were mixed with $500 \mu \mathrm{L}$ of $0.067 \mathrm{M}$ freshly prepared aqueous solution of TNBS (Sigma), an equivalent of $\mathrm{KOH}(330 \mu \mathrm{L}$ of $0.1 \mathrm{M}$ solution), $500 \mu \mathrm{L}$ of $0.05 \mathrm{M}$ borate buffer ( $\mathrm{pH} 8.5)$ and water up to the total volume of $2.0 \mathrm{~mL}$ and heated during $1 \mathrm{~h}$ in a thermostat at $50{ }^{\circ} \mathrm{C}$. The absorbances of the resulting solutions were measured at $340 \mathrm{~nm}$. Counting the number of free amino groups, which remained to be intact after maleation, gave the value of $29 \%$ that was considered to be sufficient for cross-linking.

\subsection{Preparation of Sulfated Maleated Chitosan}

Sulfated maleated chitosan was prepared according to [37]. A portion of $10 \mathrm{~mL}$ of the solution obtained under 3.3 was brought to $\mathrm{pH} 4-5,0.188 \mathrm{~g}$ of sodium metabisulfite powder was added in portions with stirring, and the solution was heated at $50{ }^{\circ} \mathrm{C}$ for $3 \mathrm{~h}$, maintaining the $\mathrm{pH}$ within $4-5$ by adding $1 \mathrm{M}$ sulfuric acid. The solution was centrifuged at $2750 \mathrm{rpm}$ for $3 \mathrm{~min}$, the upper layer was separated and dialyzed against water for $19 \mathrm{~h}$.

\subsection{Preparation of Carboxymethylated Chitosan}

Carboxymethylated chitosan was prepared according to [36]. A total of $800 \mathrm{mg}$ of chitosan was dissolved in $80 \mathrm{~mL}$ of $0.5 \% \mathrm{HCl}$ and stirred for a day at room temperature for dissolving. Ten milliliters of this solution was mixed with $10 \mathrm{~mL}$ of $3 \mathrm{M} \mathrm{KOH}$ dissolved in ethanol:water $(2: 1, v / v)$ while stirring. The precipitate of chitosan was centrifuged at $2750 \mathrm{rpm}$ for $2 \mathrm{~min}$ and then washed with water. The chitosan residue was dispersed in water with added $0.7 \mathrm{~g}$ of sodium chloroacetate (total volume $6 \mathrm{~mL}, \mathrm{pH} 13$ ) and placed on an orbital shaker for a day. The suspension was neutralized to $\mathrm{pH} 8$, filtered and acetone was added until the formation of a white precipitate, which was separated, washed with a 
3:1 mixture of methanol/water and dissolved in $7 \mathrm{~mL}$ of $1.2 \mathrm{mmol}$ of acetic acid to obtain a solution with $\mathrm{pH} 3.8$.

\subsection{Labeling of Chitosans with Rhodamine B}

All types of anated chitosan were modified with Rhodamine B isothiocyanate (RITC) according to [45]: 2,0 mL of ethanolic RITC (0.7 mM) solution was added to a $0.045 \mathrm{M}$ modified chitosan solution $(2 \mathrm{~mL})$ and kept for a day at room temperature. Then, the mixture was dialyzed against water for two days with several changes of the external solution.

\subsection{Preparation of Containers Dye-PHMG-Ceftriaxone-Chitosan}

The solutions: 0.0056 M PHMG $(6 \mathrm{~mL}), 0.1 \mathrm{~g} / \mathrm{L}$ dye $(380 \mu \mathrm{L})$ and $0.005 \mathrm{M}$ ceftriaxone $(3 \mathrm{~mL}$ ) were mixed in a plastic test-tube, and $450 \mu \mathrm{L}$ of $0.045 \mathrm{M}$ solution of an anated chitosan (or $900 \mu \mathrm{L}$ of $0.022 \mathrm{M}$ chitosan labeled with RITC) was added. The formed precipitate was centrifuged at 10,000 rpm for $2 \mathrm{~min}$ and washed with water. Next, 50\% glutaralehyde $(220 \mu \mathrm{L})$ and water to the final volume of $15 \mathrm{~mL}$ were added. The $\mathrm{pH}$ of the solution was adjusted to 7.0-7.3 with $1 \mathrm{M} \mathrm{KOH}$ and the suspension was stored at room temperature for $24 \mathrm{~h}$ for cross-linking. Then, the containers were ultrasonically dispersed and dialyzed against water for $30 \mathrm{~min}$.

\subsection{Cell Culture and Endocytosis}

MCF7 (ATCC ${ }^{\circledR}$ Cat. No. HTB-22 ${ }^{\mathrm{TM}}$ ) breast adenocarcinoma cells were cultivated in Thermo Scientific ${ }^{\mathrm{TM}}$ Nunc $^{\mathrm{TM}}$ Lab-Tek $^{\mathrm{TM}}$ II chambered coverglass cells in DMEM medium (Gibco, Paisley, UK) supplemented with 10\% of fetal bovine serum (FBS, Gibco, UK), pyruvate (Gibco, Paisley, UK), glutamine (Gibco, Paisley, UK) and antibiotics and antimycotic (Gibco, Paisley, UK) at $37{ }^{\circ} \mathrm{C}$ with $5 \% \mathrm{CO}_{2}$. To every chamber, $300 \mu \mathrm{L}$ of cross-linked quaternary container dye-PHMG-ceftriaxone-chitosan was added. Cells were incubated at $37{ }^{\circ} \mathrm{C}$ with $5 \% \mathrm{CO}_{2}$ for $40 \mathrm{~min}$, the solution was removed, cells were washed with PBS and fixed with $4 \%$ formaldehyde in PBS for $15 \mathrm{~min}$. A total of $500 \mu \mathrm{L}$ of conservation mixture glycerol:PBS $(1: 1 v / v)$ was added to every chamber, and the samples were imaged in CLSM.

\subsection{Cytotoxicity Measurements}

MCF7 cells were seeded in a 96-well plate $\left(5 \times 10^{3}\right.$ cells/well) in $200 \mu \mathrm{L} /$ well of complete DMEM medium and incubated at $37{ }^{\circ} \mathrm{C}$ with $5 \% \mathrm{CO}_{2}$ for $48 \mathrm{~h}$. Then the medium was replaced with $100 \mu \mathrm{L} /$ well DMEM medium in the absence (control) or presence of various amounts of the tested compounds and incubated at $37^{\circ} \mathrm{C}$ with $5 \% \mathrm{CO}_{2}$ for $24 \mathrm{~h}$; $10 \mu \mathrm{L} /$ well WST-1 solution (CELLPRO-RO Roche, Basel, Switzerland) was added to each well and incubated under culture conditions for $2 \mathrm{~h}$. The absorbance of the samples was measured at $450 \mathrm{~nm}$.

\section{Conclusions}

We suggested a feasible approach for monitoring of the delivery of large hydrophilic compounds into eukaryotic cells. The technique is based on the aggregate formation of the delivered compound linked with an oppositely charged ion and a hydrophobic dye, followed by its encapsulation into a polyelectrolyte container. The strategy is demonstrated using the ceftriaxone-PHMG-carbocyanine dye system in the containers of dialdehydecrosslinked maleated chitosan, penetrating across the membrane of human breast adenocarcinoma cells. The containers are shown to have low toxicity and high temporal stability.

As a prospect for the future, other potent systems should be developed that would allow the difference between the bound and free drug in the cell to be clearly distinguished in order to observe the in vivo degradation of containers in the course of time. We consider such methodology will pave the way for real-time imaging-guided delivery of hydrophilic drugs. 
Supplementary Materials: The following materials are available online, Dye synthesis protocol; Figure S1: Sizes of container particles chitosan-PHMG-dye-ceftriaxone and their components obtained by dynamic light scattering technique: a-by intensity, b-by number; Figure S2: FT-IR spectra of the solid samples of chitosan, carboxymethylated, maleated, and maleated sulfated chitosan; Figure S3. Transmission electron microscope images of containers maleated chitosan-PHMG-dye and noncross-linked aggregates PHMG-dye-ceftriaxone-maleated chitosan; Figure S4: CLSM images of cells after contact with the suspension of containers ceftriaxone-PHMG-dye-maleated chitosan or the respected control solutions (maleated chitosan alone, PHMG-dye-chitosan, and dye alone) and the fluorescense spectra obtained in CLSM; Figure S5: All optical sections of CLSM Z-stack images of cells incubated with containers PHMG-dye-ceftriaxone in maleated chitosan.

Author Contributions: Conceptualization, M.K.B. and G.G.K.; methodology, T.A.P., A.A.E. and N.L.K.; investigation, S.A.Z., M.I.L., A.N.L., I.A.D., K.Y.V., V.M.S., A.A.B., S.S.A., A.A.E.; writingoriginal draft preparation, S.A.Z.; writing-review and editing, M.K.B., N.L.K.; supervision, M.K.B.; funding acquisition, M.K.B. All authors have read and agreed to the published version of the manuscript.

Funding: This research was funded by Russian Foundation for Basic Research, grant number 20-0300334a.

Institutional Review Board Statement: Not applicable.

Informed Consent Statement: Not applicable.

Data Availability Statement: Not applicable.

Acknowledgments: Authors thank Aleksey Dobrotvorsky (photodrom.com) for providing NIR visualizing equipment, Irina Stepanova for the synthesis of sulfated chitosans, Alexander Dityuk for donating PHMG samples, and N.A. Paramonov for language advice.

Conflicts of Interest: The authors declare no conflict of interest. The funders had no role in the design of the study; in the collection, analyses, or interpretation of data; in the writing of the manuscript, or in the decision to publish the results.

Sample Availability: Not applicable.

\section{Appendix A. Estimation of the Stability Constant of Aggregate Ceftriaxone-PHMG-Dye}

As the concentration of dye was kept much lower than that of the other components (see conditions in the caption to Figure 3), the dependences of the fluorescence intensity on the concentrations of ceftriaxone and PHMG could be used for the calculations. Material balance equation was written for the dye only: $c(\mathrm{D})=[\mathrm{D}]+[\mathrm{PCD}]$; for the polymer and ceftriaxone it was assumed that $c(\mathrm{P}) \mathrm{H}[\mathrm{P}]$, and $c(\mathrm{C}) \mathrm{H}[\mathrm{C}]$. Since PCD was regarded as the only emitting species, the emission intensity $I$ was written as $I=\Sigma[\mathrm{PCD}]$, where $\sum$ is an empirical coefficient. Hence, $K=\frac{I / \varepsilon}{c(\mathrm{P}) \cdot c(\mathrm{C}) \cdot(c(\mathrm{D})-I / \varepsilon)}$. On rearrangement, the following expression can be obtained: $\frac{1}{I}=\frac{1}{\varepsilon \cdot c(\mathrm{D})}+\frac{1}{\varepsilon \cdot c(\mathrm{D}) \cdot K \cdot c(\mathrm{P}) \cdot c(\mathrm{C})}$, or $y=A+B x$, where $x=1 / c(\mathrm{P})($ for the varied ceftriaxone concentration) or $x=1 / c(C)$ (for the varied PHMG concentration); $A$ $=\frac{1}{\varepsilon \cdot c(\mathrm{D})}$ and $B=\frac{1}{\varepsilon \cdot c(\mathrm{D}) \cdot K \cdot c(\mathrm{C})}\left(\right.$ or $\left.B=\frac{1}{\varepsilon \cdot c(\mathrm{D}) \cdot K \cdot c(\mathrm{P})}\right)$. By constructing the graphs in coordinates $1 / I-1 / c(\mathrm{P})$ or $1 / I-1 / c(\mathrm{C})$ and finding the regression coefficients $A$ and $B$, the $K$ value was calculated as $K=\frac{1}{B \cdot \varepsilon \cdot c(D) \cdot c(C)}=\frac{A}{B \cdot c(C)}\left(\right.$ or $K=\frac{A}{B \cdot c(P)}$ for varied $P$ ) (Table 1). Only the linear portions of the graphs with coefficients of determination $\left(R^{2}\right)$ exceeding 0.90 were used for calculations (the concentration ranges used are shown in Table 1).

To evaluate the feasibility of formation of aggregates of a different composition $(\mathrm{mP}+$ $\left.n \mathrm{C}+\mathrm{D}=\mathrm{P}_{m} \mathrm{C}_{n} \mathrm{D}\right)$, the stability constant was written as

$$
K=\frac{\left[\mathrm{P}_{\mathrm{m}} \mathrm{C}_{\mathrm{n}} \mathrm{D}\right]}{[\mathrm{P}]^{m}[\mathrm{C}]^{n}[\mathrm{D}]}
$$

Either $m$ or $n$ was supposed to exceed 1 . It can be demonstrated arithmetically that the $K$ values for this case could be obtained from the plots of $1 / I$ vs. $1 / c(P)^{m}$ and $1 / c(C)^{n}$. This 
work was done for the experimental data with $m$ and $n$ equal to 2 . The result shows that the values of $n$ and $m$ greater than 1 yield lower values of the coefficients of determination $\left(R^{2}\right.$, Table 1). It can be concluded that the most probable composition of the aggregate is 1:1:1 (P:C:D).

\section{References}

1. Sung, Y.K.; Kim, S.W. Recent advances in polymeric drug delivery systems. Biomater. Res. 2020, 24, 12. [CrossRef]

2. Mitchell, M.J.; Billingsley, M.M.; Haley, R.M.; Wechsler, M.E.; Peppas, N.A.; Langer, R. Engineering precision nanoparticles for drug delivery. Nat. Rev. Drug. Discov. 2021, 20, 101-124. [CrossRef]

3. Xu, X.-D.; Zhao, L.; Qu, Q.; Wang, J.-G.; Shi, H.; Zhao, Y. Imaging-guided drug release from glutathione-responsive supramolecular porphysome nanovesicles. ACS Appl. Mater. Interfaces 2015, 7, 17371-17380. [CrossRef]

4. Carmona, T.; Marcelo, G.; Rinaldi, L.; Martina, K.; Cravotto, G.; Mendicuti, F. Soluble cyanine dye/ $\beta$-cyclodextrin derivatives: Potential carriers for drug delivery and optical imaging. Dyes Pigm. 2015, 114, 204-214. [CrossRef]

5. Wu, J.B.; Shi, C.; Chu, G.C.; Xu, Q.; Zhang, Y.; Li, Q.; Yu, J.S.; Zhau, H.E.; Chung, L.W. Near-infrared fluorescence heptamethine carbocyanine dyes mediate imaging and targeted drug delivery for human brain tumor. Biomaterials 2015, 67, 1-10. [CrossRef]

6. Hassan, U.A.; Hussein, M.Z.; Alitheen, N.B.; Yahya Ariff, S.A.; Masarudin, M.J. In vitro cellular localization and efficient accumulation of fluorescently tagged biomaterials from monodispersed chitosan nanoparticles for elucidation of controlled release pathways for drug delivery systems. Int. J. Nanomed. 2018, 13, 5075-5095. [CrossRef]

7. Feng, T.; Ai, X.; An, G.; Yang, P.; Zhao, Y. Charge-convertible carbon dots for imaging-guided drug delivery with enhanced in vivo cancer therapeutic efficiency. ACS Nano 2016, 10, 4410-4420. [CrossRef]

8. Cui, W.; Lu, X.; Cui, K.; Wu, J.; Wei, Y.; Lu, Q. Fluorescent nanoparticles of chitosan complex for real-time monitoring drug release. Langmuir 2011, 27, 8384-8390. [CrossRef]

9. Larrañeta, E.; Stewart, S.; Ervine, M.; Al-Kasasbeh, R.; Donnelly, R.F. Hydrogels for hydrophobic drug delivery. classification, synthesis and applications. J. Funct. Biomater. 2018, 9, 13. [CrossRef]

10. Park, M.K.; Deng, S.; Advincula, R.C. Sustained release control via photo-cross-linking of polyelectrolyte layer-by-layer hollow capsules. Langmuir 2005, 21, 5272-5277. [CrossRef] [PubMed]

11. Wang, H.; Mukherjee, S.; Yi, J.; Banerjee, P.; Chen, Q.; Zhou, S. Biocompatible chitosan-carbon dot hybrid nanogels for NIRimaging-guided synergistic photothermal-chemo therapy. ACS Appl. Mater. Interfaces 2017, 9, 18639-18649. [CrossRef]

12. Lim, E.K.; Sajomsang, W.; Choi, Y.; Jang, E.; Lee, H.; Kang, B.; Kim, E.; Haam, S.; Suh, J.S.; Chung, S.J.; et al. Chitosan-based intelligent theragnosis nanocomposites enable $\mathrm{pH}$-sensitive drug release with MR-guided imaging for cancer therapy. Nanoscale Res. Lett. 2013, 8, 467. [CrossRef]

13. Cho, H.S.; Dong, Z.; Pauletti, G.M.; Zhang, J.; Xu, H.; Gu, H.; Wang, L.; Ewing, R.C.; Huth, C.; Wang, F.; et al. Fluorescent, superparamagnetic nanospheres for drug storage, targeting, and imaging: A multifunctional nanocarrier system for cancer diagnosis and treatment. ACS Nano 2010, 4, 5398-5404. [CrossRef]

14. Kozuch, D.J.; Ristroph, K.; Prud'homme, R.K.; Debenedetti, P.G. Insights into hydrophobic ion pairing from molecular simulation and experiment. ACS Nano 2020, 14, 6097-6106. [CrossRef] [PubMed]

15. Maha, A.H.; Al-Dujaili, E. Hydrophobic ion-paired drug delivery system: A review. Indian Drugs 2020, 57, 7-18. [CrossRef]

16. Asfour, M.H.; Kassem, A.A.; Salama, A.; Abd El-Alim, S.H. Hydrophobic ion pair loaded self-emulsifying drug delivery system (SEDDS): A novel oral drug delivery approach of cromolyn sodium for management of bronchial asthma. Int. J. Pharm. 2020, 585, 119494. [CrossRef] [PubMed]

17. Shaker, D.S.; Ishak, R.A.H.; Ghoneim, A.; Elhuoni, M.A. Nanoemulsion: A Review on mechanisms for the transdermal delivery of hydrophobic and hydrophilic drugs. Sci. Pharm. 2019, 87, 17. [CrossRef]

18. Mahmood, A.; Bernkop-Schnürch, A. SEDDS: A game changing approach for the oral administration of hydrophilic macromolecular drugs. Adv. Drug Deliv. Rev. 2019, 142, 91-101. [CrossRef] [PubMed]

19. Tsai, M.-H.; Peng, C.-L.; Yang, S.-J.; Shieh, M.-J. Photothermal, targeting, theranostic near-infrared nanoagent with SN38 against colorectal cancer for chemothermal therapy. Mol. Pharm. 2017, 14, 2766-2780. [CrossRef]

20. Horcajada, P.; Chalati, T.; Serre, C.; Gillet, B.; Sebrie, C.; Baati, T.; Eubank, J.F.; Heurtaux, D.; Clayette, P.; Kreuz, C.; et al. Porous metal-organic-framework nanoscale carriers as a potential platform for drug delivery and imaging. Nat. Mater. 2010, 9, 172-178. [CrossRef] [PubMed]

21. Zakharenkova, S.A.; Katkova, E.A.; Doroshenko, I.A.; Kriveleva, A.S.; Lebedeva, A.N.; Vidinchuk, T.A.; Shik, A.V.; Abramchuk, S.S.; Podrugina, T.A.; Beklemishev, M.K. Aggregation-based fluorescence amplification strategy: "turn-on" sensing of aminoglycosides using near-IR carbocyanine dyes and pre-micellar surfactants. Spectr. Acta A 2021, 247, 119109. [CrossRef] [PubMed]

22. Qi, J.; Hu, X.; Dong, X.; Lu, Y.; Lu, H.; Zhao, W.; Wu, W. Towards more accurate bioimaging of drug nanocarriers: Turning aggregation-caused quenching into a useful tool. Adv. Drug Deliv. Rev. 2019, 143, 206-225. [CrossRef]

23. Li, J.; Cai, C.; Li, J.; Li, J.; Li, J.; Sun, T.; Wang, L.; Wu, H.; Yu, G. Chitosan-based nanomaterials for drug delivery. Molecules 2018, 23, 2661. [CrossRef]

24. Parhi, R. Drug delivery applications of chitin and chitosan: A review. Environ. Chem. Lett. 2020, 18, 577-594. [CrossRef] 
25. Fonseca-Santos, B.; Chorilli, M. An overview of carboxymethyl derivatives of chitosan: Their use as biomaterials and drug delivery systems. Mater. Sci. Eng. C 2017, 77, 1349-1362. [CrossRef]

26. Maji, P.; Gandhi, A.; Jana, S.; Maji, N. Preparation and characterization of maleic anhydride cross-linked chitosan-polyvinyl alcohol hydrogel matrix transdermal patch. J. Pharm. Sci. Tech. 2013, 2, $62-67$.

27. Wei, D.; Ma, Q.; Guan, Y.; Hu, F.; Zheng, A.; Zhang, X.; Teng, Z.; Jiang, H. Structural characterization and antibacterial activity of oligoguanidine (polyhexamethylene guanidine hydrochloride). Mater. Sci. Eng. C 2009, 29, 1776-1780. [CrossRef]

28. Likhachev, K.V.; Ovcharenko, E.O.; Dityuk, A.I.; Abramchuk, S.S.; Efimov, K.M.; Beklemishev, M.K. Fluorescent determination of Poly(hexamethylene Guanidine) via the aggregates it forms with quantum dots and magnetic nanoparticles. Microchim. Acta 2016, 183, 1079-1087. [CrossRef]

29. Asiedu-Gyekye, I.J.; Mahmood, S.A.; Awortwe, C.; Nyarko, A.K. A preliminary safety evaluation of polyhexamethylene guanidine hydrochloride. Int. J. Toxicol. 2014, 33, 523-531. [CrossRef]

30. Yue, X.; Liu, L.; Wu, Y.; Liu, X.; Li, S.; Zhang, Z.; Han, S.; Wang, X.; Chang, Y.; Bai, H.; et al. Preparation and evaluation of chitosan-polyvinyl alcohol/polyhexamethylene guanidine hydrochloride antibacterial dressing to accelerate wound healing for infectious skin repair. Ann. Transl. Med. 2021, 9, 482. [CrossRef]

31. Chen, J.; Wei, D.; Gong, W.; Zheng, A.; Guan, Y. Hydrogen-bond assembly of polyvinyl alcohol and polyhexamethylene guanidine for non-leaching and transparent antimicrobial films. ACS Appl. Mater. Interfaces 2018, 10, 37535-37543. [CrossRef]

32. Ceftriaxone. Available online: https://go.drugbank.com/drugs/DB01212 (accessed on 8 October 2021).

33. Kuntz, I.D., Jr.; Gasparro, F.P.; Johnston, M.D., Jr.; Taylor, R.P. Molecular interactions and the Benesi-Hildebrand equation. J. Am. Chem. Soc. 1968, 90, 4778-4781. [CrossRef]

34. Radulović, D.; Vujić, Z.; Vasiljević, M. Spectrophotometric Investigation of the celiprolol-hydrochloride ion-pair. Spectrosc. Lett. 1994, 27, 503-513. [CrossRef]

35. Singh, R.P.; Yeboah, Y.D.; Pambid, E.R.; Debayle, P. Stability constant of the calcium-citrate(3-) ion pair complex. J. Chem. Eng. Data 1991, 36, 52-54. [CrossRef]

36. Ge, H.C.; Luo, D.K. Preparation of carboxymethyl chitosan in aqueous solution under microwave irradiation. Carbohydr. Res. 2005, 340, 1351-1356. [CrossRef]

37. Gamzazade, A.I.; Nasibov, S.M. A Method for Obtaining Sulfated Chitosan. Russ. Patent No 2048475, 20 November 1995. Available online: https:/ / patenton.ru/patent/RU2048475C1 (accessed on 8 October 2021).

38. Kim, K.W.; Thomas, R.L.; Lee, C.; Park, H.J. Antimicrobial activity of native chitosan, degraded chitosan, and Ocarboxymethylated chitosan. J. Food Prot. 2003, 66, 1495-1498. [CrossRef]

39. Liu, Q.; Zhang, J.; Li, D.; Lang, J.; Zai, S.; Hao, J.; Wang, X. Inhibition of amphiphilic N-alkyl-O-carboxymethyl chitosan derivatives on Alternaria macrospora. Biomed. Res. Int. 2018, 2018, 5236324. [CrossRef] [PubMed]

40. Kiuchi, H.; Kai, W.; Inoue, Y. Preparation and characterization of poly(ethylene glycol) crosslinked chitosan films. J. Appl. Polym. Sci. 2008, 107, 3823-3830. [CrossRef]

41. Ding, Y.; Yin, H.; Shen, S.; Sun, K.; Liu, F. Chitosan-based magnetic/fluorescent nanocomposites for cell labelling and controlled drug release. New J. Chem. 2017, 41, 1736-1743. [CrossRef]

42. Yasmeen, S.; Kabiraz, M.K.; Saha, B.; Qadir, M.; Gafur, M.; Masum, S.M. Chromium (VI) ions removal from tannery effluent using chitosan-Microcrystalline cellulose composite as adsorbent. Intern. Res. J. Pure Appl. Chem. 2016, 10, 1-14. [CrossRef]

43. Ravishankar, K.; Shelly, K.M.; Desingh, R.P.; Subramaniyam, R.; Narayanan, A.; Dhamodharan, R. Green, solid-state synthesis of maleated chitosan and ionotropic gelation with chitosan. ACS Sustain. Chem. Eng. 2018, 6, 15191-15200. [CrossRef]

44. Wan Ngah, W.S.; Hanafiah, M.A.; Yong, S.S. Adsorption of humic acid from aqueous solutions on crosslinked chitosanepichlorohydrin beads: Kinetics and isotherm studies. Colloids Surf. B 2008, 65, 18-24. [CrossRef]

45. Da Trindade, M.T.; Salgado, H.R.N. Development and validation of a modern and stability-indicating method for the quantification of ceftriaxone sodium in powder for injection by infrared spectroscopy. Phys. Chem. 2017, 7, 55-62. [CrossRef]

46. Cao, C.; Wu, K.; Yuan, W.; Zhang, Y.; Wang, H. Synthesis of non-water soluble polymeric guanidine derivatives and application in preparation of antimicrobial regenerated cellulose. Fibers Polym. 2017, 18, 1040-1047. [CrossRef]

47. Mendes, A.C.; Gorzelanny, C.; Halter, N.; Schneider, S.W.; Chronakis, I.S. Hybridelectrospun chitosan-phospholipids nanofibers for transdermal drugdelivery. Int. J. Pharm. 2016, 510, 48-56. [CrossRef]

48. Katas, H.; Raja, M.A.G.; Lam, K.L. Development of chitosan nanoparticles as astable drug delivery system for protein/siRNA. Int. J. Biomater. 2013, 2013, 1-9.

49. Li, W.; Zhou, J.; Xu, Y. Study of the in vitro cytotoxicity testing of medical devices. Biomed. Rep. 2015, 3, 617-620. [CrossRef]

50. Jung, H.-N.; Zerin, T.; Podder, B.; Song, H.-Y.; Kim, Y.-S. Cytotoxicity and gene expression profiling of polyhexamethylene guanidine hydrochloride in human alveolar A549 cells. Toxicol. Vitr. 2014, 28, 684-692. [CrossRef]

51. Wiesli, M.G.; Kaiser, J.P.; Gautier, E.; Wick, P.; Maniura-Weber, K.; Rottmar, M.; Wahl, P. Influence of ceftriaxone on human bone cell viability and in vitro mineralization potential is concentration- and time-dependent. Bone Joint Res. 2021, 10, $218-225$. [CrossRef]

52. Anitha, A.; Maya, S.; Deepa, N.; Chennazhi, K.P.; Nair, S.V.; Jayakumar, R. Curcumin-loaded N,O-carboxymethyl chitosan nanoparticles for cancer drug delivery. J. Biomater. Sci. Polym. Ed. 2012, 23, 1381-1400. [CrossRef] [PubMed]

53. Sahu, S.K.; Mallick, S.K.; Santra, S.; Maiti, T.K.; Ghosh, S.K.; Pramanik, P. In vitro evaluation of folic acid modified carboxymethyl chitosan nanoparticles loaded with doxorubicin for targeted delivery. J. Mater. Sci. Mater. Med. 2010, 21, 1587-1597. [CrossRef] 
54. Bhattacharya, D.; Das, M.; Mishra, D.; Banerjee, I.; Sahu, S.K.; Maiti, T.K.; Pramanik, P. Folate receptor targeted, carboxymethyl chitosan functionalized iron oxide nanoparticles: A novel ultradispersed nanoconjugates for bimodal imaging. Nanoscale 2011, 3, 1653-1662. [CrossRef] [PubMed]

55. Anitha, A.; Maya, S.; Deepa, N.; Chennazhi, K.P.; Nair, S.V.; Tamura, H.; Jayakumar, R. Efficient water soluble O-carboxymethyl chitosan nanocarrier for the delivery of curcumin to cancer cells. Carbohydr. Polym. 2011, 83, 452-461. [CrossRef]

56. Snima, K.S.; Jayakumar, R.; Unnikrishnan, A.G.; Nair, S.V.; Lakshmanan, V.-K. O-Carboxymethyl chitosan nanoparticles for metformin delivery to pancreatic cancer cells. Carbohydr. Polym. 2012, 89, 1003-1007. [CrossRef] [PubMed]

57. Izco, J.M.; Torre, P.; Barcina, Y. Ripening of ossau-iraty cheese: Determination of free amino acids by RP-HPLC and of total free amino acids by the TNBS method. Food Control 2000, 11, 7-11. [CrossRef] 